Res Publica. Revista de Historia de las Ideas Políticas ISSN-e: 1989-6115

http://dx.doi.org/10.5209/RPUB.63896

\title{
El concepto de lo político de Carl Schmitt. Versión de 1927
}

\author{
Santiago M. Zarria*; Günter Maschke**
}

Sumario: 1. Introducción. 2. Versiones de El Concepto de lo Político desde 1927 a 2018. 3. Proposiciones estructurales de El Concepto de lo Político versión de 1927. 4. El Concepto de lo Político [1927].

Cómo citar: Zarria, S. M.; Maschke, G. (2019). El concepto de lo político de Carl Schmitt. Versión de 1927, en Res Publica 22.1, 259-289

\section{Introducción}

Carl Schmitt forma parte de los pocos intelectuales que han causado al mismo tiempo desprecio y admiración, fascinación y repulsión. Para algunos es un amigo y un provocador oponente intelectual, para otros es un enemigo. Un espíritu peligroso $^{1}$. Un "cuervo blanco que no falta en toda lista negra" ${ }^{2}$ "que hable sobre el destino del pueblo alemán [Schicksal Deutschlands]. Por ejemplo, para Taubes, Schmitt (junto a Heidegger) es la potencia espiritual que superó de largo a todo el desorden intelectual, pero también, dice Taubes, que todo profesor adjunto de Ciencias Políticas debe patear el culo [Arsch] de Carl Schmitt en su primera clase, porque el concepto de amigo-enemigo no son las categorías correctas ${ }^{33}$. La síntesis de los afectos y efectos que provoca la obra y figura de Schmitt podría formularse así: "Genial, aber gefährlich und abgründig"'. Creador y destructor simultáneamente.

Todavía hoy, Carl Schmitt es una mala palabra en Alemania. Este irremediable descrédito se debe en gran parte a su adhesión al nacionalsocialismo y a la justifica-

Filósofo y Politólogo. Actualmente, Goethe-Universität Frankfurt am Main.

** Editor de varias obras de Carl Schmitt y referente indiscutible dentro de los estudios schmittianos. Günter Maschke mantuvo contacto personal y epistolar hasta la muerte de Carl Schmitt y es uno de los pocos discípulos directos de Schmitt que todavía se encuentran entre nosotros.

1 J. W, Müller, Ein gefährlicher Geist. Carl Schmitts Wirkung in Europa, Wiss. Buchges, Darmstadt, 2007.

2 "Schließlich genügt: C. S. geb. 1888, weißer Rabe, der auf keiner schwarzen Liste fehlt" (C. Schmitt, Carl Schmitt--Briefwechsel mit einem seiner Schüler. Akademische Verlag, Berlin, 1995, p. 186). Esta cita también aparece en R, Mehring, Carl Schmitt, Aufstieg und Fall, Verlag C. H. Beck, München, 2009, p. 13.

3 Cf. J, Taubes, Ad Carl Schmitt Gegenstrebige Fügung. Merve Verlag, Berlin, 1987, pp. 31, 76.

4 "Genial, pero peligroso y abismal", en G, Maschke, Im Irrgarten Carl Schmitts en Korino, Intellektuelle im Bann des Nationalsozialismus, vorwort von Ebehard Jäckel, Hoffmann und Campele Verlag, Hamburg, 1980, p. 204. 
ción y legitimación jurídica de las acciones del Führer. No fue el acto de un simple aventurero intelectual, sino de un Diabolus de la constitución ${ }^{5}$. Otra razón, no menos importante, se debe a la sucesiva adaptación que el propio Schmitt realizó a una de sus obras más conocidas durante la efervescencia nazi ${ }^{6}$ : El Concepto de lo Político [Der Begriff des Politischen], en 1932 y 1933, con la cual sembró y cosechó hostili$\operatorname{dad}^{7}$. Sin duda alguna, El Concepto de lo Político es un texto al que se puede aplicar, irónicamente, la misma sentencia que el propio Schmitt dio sobre el Leviatán de Hobbes: Carl Schmitt se hizo más famoso y tristemente célebre por El Concepto de lo Político que por el resto de su obra ${ }^{8}$.

Las acciones mencionadas lo llevaron a ser considerado no solo como el jurista de la corona del Tercer Reich [Kronjurist des Dritten Reiches], sino que también, visto en conjunto la influencia y repercusión de su obra, lo han convertido en uno de los pensadores, teóricos políticos, más controversiales y significativos del siglo XX. Carl Schmitt es un clásico del pensamiento político ${ }^{9}$, a la altura de Hobbes, Ma-

5 Sobre las afirmaciones: "aventurero intelectual” y "jurista aventurero" ver: C, Schmitt, Carl Schmitt: Antworten in Nürnberg. Herausgegeben und kommentiert von Helmut Quaritsch, Duncker \& Humblot, 2000, pp. 28, 4041, 60. También: "Das Picaro-Argument: Ich bin ein «intellektueller Abenteurer», ein ironischer Spieler! Die Langeweile des Lebens ist nur aufzuhalten, wenn man es ins Spiel hebt!" en R, Mehring, Carl Schmitt: Aufstieg und Fall, CH Beck, 2009, p. 312. [Argumento Pícaro: "Soy un aventurero intelectual, un jugador irónico. El tedio de la vida es soportable sólo cuando se la pone en juego"].

Sobre el Diabolus: K, Sontheimer, Der Macht näher als dem Recht en Die Zeit vom 16.04.1985.

6 A. Sobre su adhesión, según Jaspers, tanto Schmitt como Heidegger, en su pretensión de situarse en la cima intelectual del nacionalsocialismo, lo único que consiguieron fue empeñar su trayectoria intelectual, obviamente "para desgracia de la reputación de la filosofía alemana" (C. Jaspers a Oehlkers, Heidelberg, 22. XII. 1945 en H, Ott, Matin Heidegger, en camino hacia su biografia, Alianza Editorial, Madrid, 1992, p. 351). Sobre el descrédito de sus obras cf. J. F. Kervégan, ¿Qué hacemos con Carl Schmitt?, Madrid, Escolar y Mayo, 2013, pp. 19-44.

B. Para Meier, Kaufmann, Rumpf, entre otros, El Concepto de lo Político es la obra clave de todo el pensamiento schmittiano, mientras que para Maschke lo es El Leviathan de Carl Schmitt (cf. M, Kaufmann, ¿Recht ohne Regel? Die philosophischen Prinzipien in Carl Schmitts Staats- und Rechtslehre, Freiburg und München, 1988, p. 15).

C. Después de la publicación de El Concepto de lo Político, segunda versión, Schmitt publicó desde 1933 hasta 1945 no menos de nueve libros, algunos completamente polémicos como, por ejemplo: Der Führer schützt das Recht de 1943, Totaler Feind, totaler Krieg, totaler Staat de 1937. Todos ellos compilados en C, Schmitt, Positionen und Begriffe. Im Kampf mit Weimar-Genf-Versailles 1923-1939, Duncker \& Humblot, Berlin, 1940. Además, en este texto Schmitt publica un extracto de El Concepto de lo Politico de 1927. Otro texto polémico publicado en 1934 fue C, Schmitt, Über die drei Arten des rechtswissenschaftliehen Denkens, Hamburg, Hanseatische Verlagsanstalt, 1934.

7 H, Meier, Carl Schmitt, Leo Strauss und Der Begriff des Politischen. Zu einem Dialog unter Abwesenden. JB Metzler, 2013, p. 11.

$8 \quad$ El texto original dice: "Hobbes ist durch den, Leviathan berühmter und berüchtigter geworden als durch sein ganzes übriges Werk" (C. Schmitt, Der Leviathan in der Staatslehre des Thomas Hobbes. Sinn und Fehlschlag eines politischen Symbols, Hanseatischen Verlagsanstalt, Hamburg, 1938, p. 9). Esta cita es la misma, solamente cambia el nombre de "Hobbes" por el de "Carl Schmitt" y "Leviathan" por "El Concepto de lo político" que Meir menciona en Carl Schmitt, Leo Strauss und Der Begriff des Politischen, pero que no cita: "Carl Schmitt ist durch den Begriff des Politischen berühmter und berüchtigter geworden als durch sein ganzes übriges Werk" (H, Meier, op. cit., p. 11).

9 "Hoy parece claro: un autor al que cada año se le dedican decenas de obras y artículos en el mundo entero forma parte, guste o no, del patrimonio común; con otras palabras: es un clásico” (J. F. Kervégan, op. cit., p. 9). Véase las razones del por qué se puede considerar a Schmitt como un clásico: B. Willms, Carl Schmitt - jüngster Klassiker des politischen Denkens? en H. Quaritsch (ed.), Complexio oppositorum Über Carl Schmitt. Duncker \& Humblot, Berlin, 1988, pp. 577-597. B, Schlink, ¿Why Carl Schmitt? Constellations, vol. 2, no 3, Blackwell Publishers, Oxford, 1996, pp. 429-441. Cf. J. W. Bendersky, Carl Schmitt Theorist for the Reich, Princeton, Princeton University Press, 1983, p. x. 
quiavelo y Weber. Cuestión que no ha cesado ${ }^{10}$; ya que, en lo que va del siglo XXI, el interés-crítico por la obra schmittiana, con y contra Schmitt, se ha renovado y no hay que dejarla solamente en manos de la schmittolatría, los apologistas del punto y coma schmittiano, como tampoco en la de sus difamadores ${ }^{11}$. Carl Schmitt sigue siendo un pensador diabólicamente interesante ${ }^{12}$, porque todavía hoy, como dice Habermas, continúa dividendo espíritus ${ }^{13}$.

El 23 de septiembre de 1926, Schumpeter viaja a Heidelberg por cuestiones relativas al Archivo para Ciencia Social y Política Social [Archiv für Sozialwissenschaft und Sozialpolitik] y se encuentra con la grata noticia de que su antiguo colega de la Universidad de Bonn en los años veinte, Carl Schmitt, preparaba un texto que, según él, no podría ser reemplazado por otro que hable mejor a los lectores sobre ese problemático tema, es decir, sobre lo político ${ }^{14}$. Un año más tarde, en septiembre de 1927, se publica la primera versión, en forma de artículo, de El Concepto de lo Político $^{15}$ (CdP).

A partir de entonces, desde 1927 hasta 1963, la versión original de CdP ha variado por cambios que el propio Schmitt insertó en el texto. De las tres versiones: $1927,1932 / 1963,1933$, se ha publicado en español las de 1932 y 1933. Esto quiere decir que durante más de setenta y ocho años -desde la primera traducción al español realizada por Francisco Javier Conde y publicada en España, en 1941, en Estudios Políticos, hasta las sucesivas ediciones realizadas por Alianza Editorial a partir de 1991 - no se ha utilizado la versión original del CdP, sino la del 32 y 33, versiones ${ }^{16}$

10 Por ejemplo, A. De Benoist, Carl Schmitt: Internationale Bibliographie der Primär-und Sekundärliteratur, Ares Verlag, 2010; J. Meierhenrich y O. Simons, (eds.), The Oxford Handbook of Carl Schmitt, Oxford University Press, 2016. S. A. Mousavi, Die Globalisierung und das Politische: Überlegungen zur Aktualität von Carl Schmitt. Duncker \& Humblot, 2017.

11 Las referencias sobre el punto medio schmittiano pueden verse en von Bredow: "das Werk Carl Schmitts zu intelligent geschrieben und zu wichtig, als daß es in den Händen von Apologeten und Anti-Apologeten eingesäuert werden sollte", en W, Bredow, Carl Schmitt lesen, en Liberal, Nr. 20, 1978, pp. 432-444. Bendersky retoma esta idea en Carl Schmitt Theorist for the Reich, W. Bendersky, op. cit., p. xi.

12 "In jedem Fall ist Schmitt ein teuflisch interessanter Denker, inzwischen weltweit in der Diskussion, ob in Deutschland, Spanien oder Italien, ob in den USA oder in Japan" (H. Ottmann. Geschichte des politischen Denkens: Band 4.1: Das 20. Jahrhundert. Der Totalitarismus und seine Überwindung. Springer-Verlag, 2016, p. 215). Cf. también: J. W. Müller, Ein gefährlicher Geist. Carl Schmitts Wirkung in Europa, Wissenschaftliche Buchgesellschaft, Darmstadt, 2007.

13 J. Habermas, "Carl Schmitt: los terrores de la autonomía" en Identidades nacionales y post nacionales, Madrid, Tecnos, 1989, p. 67.

14 Cf. J. A. Schumpeter, Briefe/Letters. Selected and edited by U. Hedtke and R. Swedberg, Tübingen, Mohr Siebeck, 2000; C. Schmitt, Frieden oder Pazifismus? Arbeiten zum Völkerrecht und zur internationalen Politik 1924-1978. Herausgegeben, mit einem Vorwort und mit Anmerkungen versehen von Günter Maschke, Berlin: Duncker \& Humblot, 2005, p. 133.

15 Dos cuestiones sobre el texto: a) A Der Begriff des Politischen le antecedieron dos nombres: "historia del estado" y "teoría del estado" aunque, finalmente, Schmitt decidió llamarlo: Der Begriff des Politischen (cf. R. Mehring, op. cit., p. 202); b) El 15 de noviembre de 1927, luego de la muerte de Ball, en una carta, Schmitt le dice a Muth que cada palabra de Der Begriff des Politischen estaba dirigida a Hugo Ball (P. Tommissen, "Der Briefwechsel zwischen Carl Muth und Carl Schmitt" in Politisches Denken Jahrbuch 1998 [pp. 127-159], JB Metzler, Stuttgart, 1998, p.144). En 1924, Ball escribió Carl Schmitts Politische Theologie, en el que elogia la "inteligencia inquisitoria" [inquisitorische Intelligenz] de Schmitt. Ese ensayo convertía a Ball en un intérprete agudo de Schmitt, además de ser la primera reseña sustancial de la obra schmittiana. Tal fue la impresión de Schmitt que hablaron de la posibilidad de una nueva edición de Politischen Romantik con una introducción de Ball (cf. E. Kennedy, Carl Schmitt und Hugo Ball. Ein Beitrag zum Thema politischer Expressionismus, Zeitschrift für Politik 35, n. 2, 1988, pp. 143-62).

16 Dado que este trabajo forma parte de una investigación más amplia que agrupa las tres versiones: $1927-$ 1932/1963-1933, la discusión teórica sobre la variación de El Concepto de lo Político en sus tres versiones no 
que Schmitt adaptó, como ya se advirtió, de acuerdo al espíritu de la época. El que quiere hablar con lobos, como dice Quaritsch ${ }^{17}$, debe aullar con lobos, y Schmitt lo hizo con el nacionalsocialismo ${ }^{18}$.

Por esta razón, el objetivo de este texto es doble: mostrar de forma general la evolución que ha tenido el CdP en sus diferentes versiones a partir de sus publicaciones tanto en alemán como en español; y presentar el texto completo de 1927 cuya versión se realiza por primera vez en español. Con esto se llena un vacío sustancial de una de las obras clave en el pensamiento schmittiano que aún no se había publicado en español.

Este artículo se encuentra dividido de la siguiente manera: en primer lugar, se presenta las versiones que ha tenido el CdP tanto en alemán (Tabla 1) como en español (Tabla 2). Luego, se expone las ideas centrales de cada capítulo del CdP de 1927 en forma de proposiciones categóricas simples; finalmente, se presenta la versión completa de El Concepto de lo Político ${ }^{19}$, texto que conserva la estructura original de la publicación realizada en el Archiv für Sozialwissenschaft und Sozialpolitik en 1927.

\section{Versiones de El Concepto de lo Político desde 1927 a 2018}

El Concepto de lo Político ${ }^{20}$ [CdP] se publica por primera vez en 1927, como un artículo, en el Archiv für Sozialwissenschaft und Sozialpolitik [Archivo de Ciencia

forma parte de esta publicación. Esta discusión será abordada por una próxima publicación: Reconstrucción de lo político.

17 H. Quaritsch, Positionen und Begriffe Carl Schmitts, Duncker \& Humblot, Berlin, 1995, p. 83.

18 Con la traducción del CdP de 1933 se expandió la figura de un Schmitt nazi [Schmitt's Form des Nazi in Europa] en forma de libro al resto de Europa, luego a Latinoamérica, Asia y más tarde a EE. UU (Cf. A. De Benoist, Carl Schmitt: Internationale Bibliographie der Primär-und Sekundärliteratur, op. cit.; J. F. Kervégan, ¿Qué hacemos con Carl Schmitt?, op. cit., pp. 45-62. Sobre la recepción en España, Italia y Francia: G. Maschke, Carl Schmitt in Europa: Bemerkungen zur italienischen, spanischen und französischen Nekrologdiskussion, Der Staat, Vol. 25, No. 4, Duncker \& Humblot, 1986, pp. 575-599.

19 La aproximación de esta versión al español es inédita y se hace desde el conocimiento de la obra schmittiana. Esta versión de El Concepto de lo Político de 1927 no hubiera sido posible sin la comprometida colaboración del profesor Günter Maschke quien, pese a su delicado estado de salud, otorgó tiempo a la lectura, revisión y presentación de sugerencias esenciales al texto durante las reuniones de trabajo. Al profesor Dr. Wladimir Sierra, de la Escuela de Sociología de la Pontificia Universidad Católica del Ecuador, por la lectura y sugerencias emitidas a la versión de 1927. Al profesor. Dr. Jorge Dotti (†) de la Facultad de Filosofía y Letras de la Universidad de Buenos Aires por los comentarios al texto e información sobre las versiones publicadas en Argentina. Al profesor. Dr. Benjamin Arditi, del Centro de Estudios Políticos de la UNAM, por la valiosa información sobre las versiones del CdP en México y detalles referentes a la obra. A la profesora Dra. Margit Eckholt, directora de Das Stipendienwerk Lateinamerika-Deutschland, ya que, dentro del marco de la beca recibida por esta institución se ha realizado la presente versión. Al profesor Dr. Fernando Barredo S.J, Vicerrector de la Pontificia Universidad Católica del Ecuador y miembro de Kuratorium alemán en Quito, Ecuador. A la profesora Dra. Alexandra Vela Puga, Decana de la Facultad de Derecho de la Universidad de las Américas; y, finalmente, al archivo del Institut für Sozialforschung [Instituto de Investigación Social], más conocido como Escuela de Frankfurt, por haberme otorgado una copia de El Concepto de lo político de 1927.

20 No se sabe con exactitud "por qué" Schmitt decidió cambiar die Politik (la política) por das Politische (lo político). ¿La distinción entre la política y lo político es realmente tan importante? En su Tagebücher 1925 bis 1929 se puede encontrar referencias sobre la ambigüedad de su uso, por ejemplo, el 31 de marzo de 1927, Schmitt escribe: "Morgens diktiert bei Frau Schneider über den Begriff der Politik, müde, mudos..." El 12 de abril de 1927: "Morgens ein Aufsatz über Politik fertig gemacht und zur Post gebracht. Frohlich, das erledigt zu haben". E1 23 de abril del mismo año: “Abends ... Gespräch mit Oberheid und Petterson über das politische Universum, 
Social y Política Social] de Heidelberg. En 1928, aparece en Probleme der Demokratie [Problemas de la Democracia] en Berlín y en Das neue Ufer. Kulturelle Beilage der Germania [La Nueva Orilla. Suplemento Cultural de Germania]. En el 2005, aparece nuevamente la versión del 27, en forma de artículo dentro de Frieden oder Pazifismus [Paz o Pacifismo], texto editado por Günter Maschke. En 1932, la editorial Duncker \& Humblot lo publicó por primera vez en forma de libro y en 1933 lo hizo la Hanseatischen Verlagsanstalt.

Hasta ahí, el CdP cuenta con tres versiones. No obstante, en 1963, Schmitt autoriza la reimpresión de la versión de 1932 y no la de 1933, que no solo era la última en la que había trabajado, sino la más desarrollada de acuerdo al ambiente político ${ }^{21} \mathrm{en}$ el que se publicó. Esta versión, tal como lo dice en el prólogo, es la reimpresión del CdP de 1932, completa y sin modificaciones en lo medular ${ }^{22}$, pero sí en la estructura del texto, porque añadió las indicaciones, el índice y el prólogo fueron corregidos. El mismo año, de forma coincidente, apareció Theorie des Partisanen. Zwischenbemerkung zum Begriff des Politischen [Teoría del Partisano. Acotación al concepto de lo político]. Finalmente, Duncker \& Humblot publicó en julio 2018, un texto que reúne las tres versiones en forma sinóptica: Der Begriff des Politischen: Synoptische Darstellung der Texte [El Concepto de lo Político. Presentación sinóptica de los textos $^{23}$ ], edición de Marco Walter. Pero éste no es el primer texto que reúne las tres versiones del CdP, Alexandre Franco de Sá ya lo hizo en el 201524. Tomando como referencia la versión de 1932, va insertando en una serie de notas las variaciones que presentan las tres versiones.

A continuación, se presenta la serie cronológica de las tres versiones. Para distinguirlas se utilizará, en español, El Concepto de lo Político: CdP 1; segunda, CdP 2 y tercera, CdP 3 y en alemán Der Begriff des Politischen: BP 1, BP 2, BP 3.

das vom Christentum vorausgesetz wird"; y, el 4 de mayo del mismo año: "Schöne Vorlesung, las meinen Aufsatz über den Begriff des Politischen vor, großer Erfolg”. (C. Schmitt, Tagebücher 1925 bis 1929, Hrsg. von Martin Tielke und Gerd Giesler, Duncker \& Humblot, Berlin, 2018, pp. 131-137).

21 La incursión formal de Schmitt en el Nacionalsocialismo se produjo el 1 de mayo de 1933 con su afiliación al partido nazi. Su número fue: 2.098.860. (Cf. M. Lilla, Pensadores temerarios: los intelectuales en la politica, Debate, 2004, p. 59). Sobre el ambiente político en el que se publicaron estos textos la literatura es extensa, cf. por ejemplo: P. Noack, Carl Schmitt. Eine Biographie, Berlin; Frankfurt/Main: Propyläen Verlag, 1993 ; H. Quaritsch, Positionen und Begriffe Carl Schmitts, Duncker \& Humblot, 1995; A. Jacobson y B. Schlink (eds), Weimar: a jurisprudence of crisis, University of California Press, 2002; E. Kennedy, Constitutional Failure: Carl Schmitt in Weimar, Duke University Press, 2004; H. Meier, Carl Schmitt, op. cit, 2013; R. Mehring, Carl Schmitt: Aufstieg und Fall, op. cit; J. Meierhenrich y O. Simons, (eds.), The Oxford Handbook of Carl Schmitt, op. cit. Cf. también, como texto complementario a M. Lauermann, Versuch über Carl Schmitt im Nationalsozialismus, in: K. Hansen, H. Lietzmann (eds.) Carl Schmitt und die Liberalismuskritik, Verlag für Sozialwissenschaften, 1988, en donde evalúa la actuación de Schmitt y describe los escritos schmittianos más relevante que se publicaron durante ese período.

22 Cf. C. Schmitt, Der Begriff des Politischen Text von 1932 mit einem Vorwort und drei Corollarien, Berlin, Duncker \& Humblot, 1933.

23 Este texto contiene: una introducción (pp. 7-33), la presentación sinóptica de las versiones: 1927-1963 (1932)1933 (pp. 55-242), que contiene dos prólogos: el de 1963 (pp. 39-48) y el de la edición italiana de 1971 (pp. 49-53), ambos escritos por Schmitt. Además, del Discurso sobre la era de las neutralizaciones y las despolitizaciones, el Epílogo al problema de 1932 y los tres corolarios (pp. 245-277). Un comentario (pp. 279-304). Indicaciones generales, (pp. 305-313) y las ilustraciones de las tres portadas. Un registro de personas (pp. 318-331) y, finalmente los agradecimientos.

24 C. Schmitt. O Conceito do Político. Introdução, tradução e notas de Alexandre Franco de Sá, Edições 70, Lisboa, 2015. Esto es algo que Marco Walter también lo reconoce en la nota 27 de la Presentación sinóptica. 
Tabla 1: Obras de El Concepto de lo Político publicadas en alemán

\begin{tabular}{|c|c|c|}
\hline VERSIÓN & AÑO & LUGAR \\
\hline BP 1 & 1927 & $\begin{array}{l}\text { Archiv für Sozialwissenschaft und Sozialpolitik. } 58 \text { Band/1Heft, Tü- } \\
\text { bingen, Verlag von J. C. B. Mohr, pp. 1-33. } \\
\text { [Texto publicado en forma de artículo] }\end{array}$ \\
\hline BP 1, a & 1928 & $\begin{array}{l}\text { Probleme der Demokratie. Schriftenreihe der Deutschen Hochschule } \\
\text { für Politik und des Institutes für Auswärtige Politik in Hamburg, vol. } \\
5 \text {. Berlin, Grunewald: Walther Rothschild, pp. 1-34. } \\
\text { [Este texto contaba con ensayos de Hermann Heller, Max Hildebert } \\
\text { Boehm, Ernst Michel y Fritz Berber. Texto publicado en forma de } \\
\text { artículo] }\end{array}$ \\
\hline BP $1, b$ & 1928 & $\begin{array}{l}\text { Der Staat und das Recht auf Krieg. Das neue Ufer, Kulturelle Bei- } \\
\text { lage, Abschnitt \# 5, } 20 \text { [21], April, Germania. } \\
\text { [El texto como tal de El Concepto de lo Político de } 1927 \text { aparece en } \\
\text { la sección } 5 \text { con el nombre: Der Staat und das Recht auf Krieg. Texto } \\
\text { publicado en forma de artículo] }\end{array}$ \\
\hline BP 1 & 1940 & $\begin{array}{l}\text { In Positionen und Begriffe. Im Kampf mit Weimar-Genf-Versailles. } \\
\text { 1923-1939. Berlin, Duncker \& Humblot, pp. } 75-83 \text {. } \\
\text { [Texto publicado en forma de artículo. Inicia con un extracto del ca- } \\
\text { pítulo cuarto, pero el quinto y sexto del CdP } 1 \text { de } 1927 \text { completos] }\end{array}$ \\
\hline BP 2 & 1932 & $\begin{array}{l}\text { Mit einer Rede uber das Zeitalter der Neutralisierungen und Ent- } \\
\text { politisierungen. Munich y Leipzig, Duncker \& Humblot, pp. 7-65. } \\
\text { [En esta versión, El CdP de } 1927 \text { se amplió, cambió y agregó: un } \\
\text { Epílogo y el Discurso sobre la era de las neutralizaciones y las despo- } \\
\text { litizaciones. Texto en forma de libro] }\end{array}$ \\
\hline BP 2 & 1963 & $\begin{array}{l}\text { Text von } 1932 \text { mit einem Vorwort und drei Corollarien, Berlin, Dun- } \\
\text { cker \& Humblot. } \\
\text { [Conserva el epílogo de 1932, añade notas y tres corolarios. Además, } \\
\text { cuenta por primera vez con un índice. Texto en forma de libro] }\end{array}$ \\
\hline BP 3 & 1933 & $\begin{array}{l}\text { Hamburg, Hanseatische Verlagsanstalt. } \\
\text { [Esta versión corresponde al CdP de 1932, modificada considerable- } \\
\text { mente y parcialmente complementada. Texto en forma de libro] }\end{array}$ \\
\hline BP 1 & 2005 & $\begin{array}{l}\text { Berlin, Duncker \& Humblot, in Frieden oder Pazifismus? Arbeiten } \\
\text { zum Völkerrecht und zur internationalen Politik 1924-1978. Heraus- } \\
\text { gegeben, mit einem Vorwort und mit Anmerkungen versehen von } \\
\text { Günter Maschke, pp. 194-239. } \\
\text { [El CdP corresponde a la versión de 1927. Al final se añade un Anexo } \\
\text { del editor.] }\end{array}$ \\
\hline BP, 1-2-3 & 2018 & $\begin{array}{l}\text { Synoptische Darstellung der Texte. Im Auftrag der Carl-Schmitt-Ge- } \\
\text { sellschaft herausgegeben von Marco Walter, Berlin, Duncker\&Hum- } \\
\text { blot. } \\
\text { [Este texto reúne de forma sinóptica las versiones: } 1927 \text { - 1932/1963 } \\
\text { - 1933] }\end{array}$ \\
\hline
\end{tabular}

Fuente: Elaboración propia con base en A, De Benoist, Carl Schmitt: Internationale Bibliographie der Primär-und Sekundärliteratur, Ares Verlag, 2010, pp. 94-95; Mehring, Carl Schmitt: Aufstieg und Fall, op. cit., p. 207; H, Meier, Carl Schmitt, Leo Strauss und Der Be- 
griff des Politischen. Zu einem Dialog unter Abwesenden, op. cit., pp. 14-15; C. Schmitt, Der Begriff des Politischen: Synoptische Darstellung der Texte. Im Auftrag der Carl-Schmitt-Gesellschaft herausgegeben von. Marco Walter. Berlin, Duncker \& Humblot, 2018, pp. 17-18.

La primera traducción de El Concepto de lo Político que se publicó en español fue la versión de 1933 y con un gran desacierto: Francisco Javier Conde tradujo [des Politischen], es decir, lo político por la política ${ }^{25}$. Este texto apareció en 1941 en Estudios Políticos. Luego, en 1975, la editorial Dolcen, lo volvió a incluir en un texto titulado: Estudios Políticos, Carl Schmitt, pero todavía no salía de Europa.

El Concepto de lo Político apareció por primera vez en Buenos Aires, Argentina, con la especificación de que el título más apropiado que el de Conde era: "Karl Schmitt. El concepto de lo Político (Der Begriff des Politischen), traducido especialmente para HECHOS E IDEAS"26. Esta traducción, según Dotti, tiene dos características: es más "fidedigna al original", porque utilizó como referencia la versión alemana de 1932 y no la versión de Conde, aunque también se conocía en Argentina, y porque no se especifica el nombre del traductor ni la fuente que lo remitió.

A partir de 1984, Struhart y Cía publican versiones sucesivas del CdP. Es necesario mencionar que existe una serie de impresiones no autorizadas publicadas por editoriales inexistentes o simplemente a nombre de editoriales reconocidas. La primera versión que publicó Struhart y Cía. fue la de Conde, en la que se incluyó una introducción de Alberto Buela. La segunda versión tuvo la fortuna de contar con una nueva traducción realizada por Eduardo Molina y Vedia y Raúl Crisafio, cuenta además con la presentación de José Aricó y se incluye La Época de las Neutralizaciones y las Despolitizaciones, los tres Corolarios: 1931, 1938 y 1950 y la Teoría del Partisano.

La versión de Molina-Crisafio, fuer reproducida en México por la editorial Folios en 1985. Esta versión tiene la particularidad de que en el título El Concepto de lo Político, político, aparece entre comillas ["político"]. No se menciona a los traductores, pero sí al editor responsable: Eduardo Mosches. Hasta aquí las versiones alternas, porque cuando Alianza Editorial adquiere los derechos de publicación de El Concepto de lo Político, descarta la versión de Conde, elige la versión schmittiana de 1932 y con la traducción de Rafael Agapito publica, por primera vez, en 1991. A partir de ahí, se imprime y publica regularmente la misma versión ${ }^{27}$. Es necesario conocer los

25 Sobre esta versión, escribe Tejada: "Hay una traducción castellana por Francisco Javier Conde incluida a las páginas 109-191 de Estudios políticos, Madrid, Cultura Española, 1941. Pero no es recomendable por adolecer de graves defectos en la versión, entre ellos la imprecisión de traducir el neutro «político» por «política» y «politicidad», debido a que el traductor realizó su trabajo siguiendo al pie de la letra la traducción italiana de D. Cantinori en los Principii politici del Nazionalsocialismo, Firenze, G. C. Sansoni, 1935, en lugar de servirse del original alemán" F. E. de Tejada, "Derecho Político" en C. E, Mascareñas y B. P. Prats, Nueva Enciclopedia Jurídica, (Vol. 1), Francisco Seix, Barcelona, 1950, p. 877.

Menciono dos ejemplos de sus textos originales, tanto de Conde como de Schmitt, que es a lo que se refiere Tejada: a) Das politische liegt nicht... [p. 16]. Lo político no ésta... / Conde traduce como La politicidad no está... [p. 123]; b) Das Politische kann.... [p. 21]. Lo político puede... / Conde traduce como La vida política puede... [p. 131]. Estas ambivalencias se encuentran a lo largo de todo el texto.

26 J. E, Dotti, Carl Schmitt en Argentina, Homo Sapiens, 2000, p. 212.

27 1991, primera edición dentro de la Colección "Alianza Universidad"; 1998 primera edición dentro de la Colección "Ensayo"; 1999 primera reimpresión; 2002 segunda reimpresión; 2005 tercera reimpresión; 2006 cuarta reimpresión; 2009 quinta reimpresión; 2014 segunda edición dentro de la Colección "Ensayo"; 2016 primera reimpresión; 2018 segunda reimpresión (actual). 
antecedentes que ha tenido esta obra fundamental en el pensamiento schmittiano; ya que, esto nos permitirá comprender la magnitud de la influencia de El Concepto de lo Político desde su primera publicación y que se expondrá en próximos artículos (ver nota 18).

A continuación, se presenta la cronología de las tres versiones publicadas en español: segunda versión, CdP 2 y tercera, CdP 3.

Tabla 2: Obras de El concepto de lo politico publicadas en español

\begin{tabular}{|c|c|c|}
\hline VERSIÓN & AÑO & LUGAR \\
\hline CdP 3 & 1941 & $\begin{array}{l}\text { Madrid, Estudios Políticos. Cultura Española, pp. 111-191. Traduc- } \\
\text { ción de Francisco Javier Conde. Contiene el Prólogo de } 1939-\sin \\
\text { numeración- de Carl Schmitt. El texto se encuentra al final de La } \\
\text { época de la neutralidad y Teología Política. } \\
\text { [El concepto de la política] }\end{array}$ \\
\hline CdP 3 & 1950 & $\begin{array}{l}\text { Buenos Aires, Hechos e Ideas. Publicación de cuestiones políticas, } \\
\text { económicas y sociales, XI, 74-75, mayo-junio, pp. 43-90. Sin otra } \\
\text { indicación que "Traducido especialmente para Hechos e Ideas. De- } \\
\text { rechos reservados". }\end{array}$ \\
\hline CdP 3 & 1975 & $\begin{array}{l}\text { Madrid, Estudios Políticos. Doncel, pp. 97-166. } \\
\text { [El concepto de la política] }\end{array}$ \\
\hline $\mathrm{CdP} 3, \mathrm{a}$ & 1984 & $\begin{array}{l}\text { en: Buenos Aires, Struhart y Cía, pp. 140. Traducción de F. Javier } \\
\text { Conde. Introducción de Alberto Buela, pp. 7-11. }\end{array}$ \\
\hline $\mathrm{CdP} 3, \mathrm{~b}$ & 1984 & $\begin{array}{l}\text { Buenos Aires, Folios, pp. 188. Traducción de Eduardo Molina y Ve- } \\
\text { dia y Raúl Crisafio. Contiene una "Presentación" de José Aricó (pp. } \\
\text { IX-XXI), una "Nota Biográfica" (pp. XXII-XXIV) y una Bibliogra- } \\
\text { fía (pp. IX-XXIV). Además, La Época de las Neutralizaciones y las } \\
\text { Despolitizaciones, los tres Corolarios de 1931, } 1938 \text { y 1950; y Teo- } \\
\text { ría del Partisano. }\end{array}$ \\
\hline CdP 3 & 1985 & $\begin{array}{l}\text { México, Folios Ediciones. (Texto de 1939), } 29 \text { de Julio. Contiene una } \\
\text { "Presentación" de José Aricó (pp. IX-XXI), una "Nota Biográfica" } \\
\text { (pp. XXII-XXIV) y una Bibliografía (pp. IX-XXIV). Además, La } \\
\text { Epoca de las Neutralizaciones y las Despolitizaciones, los tres Coro- } \\
\text { larios de 1931, } 1938 \text { y 1950; y Teoría del Partisano. Responsable de } \\
\text { edición Eduardo Mosches. No se menciona a los traductores. } \\
\text { [El concepto de lo "político"] }\end{array}$ \\
\hline $\mathrm{CdP} 2$ & 1991 & $\begin{array}{l}\text { Madrid, Alianza Editorial. El Concepto de lo Político. Texto de } 1932 \\
\text { con un prólogo y tres corolarios. Colección Alianza Universidad. } \\
\text { Versión de Rafael Agapito. Contiene una Introducción del traduc- } \\
\text { tor. Posteriormente, se publicó en la Colección "Ensayo", Alianza } \\
\text { Universidad (1998); Colección "Ciencias Sociales- Ensayo" (1999). } \\
\text { A partir de allí se mantiene de forma regular la publicación de la } \\
\text { versión de 1932. Última edición 2018. }\end{array}$ \\
\hline CdP 3 & 2001 & $\begin{array}{l}\text { México, Fondo de Cultura Económica. Carl Schmitt, Teólogo de } \\
\text { la Política. Prólogo y selección de textos de Héctor Orestes Aguilar, } \\
\text { pp. 167-223. Este texto reproduce íntegramente la versión de Folios } \\
\text { Ediciones, 1985, edición preparada por José Aricó, traducción de } \\
\text { Eduardo Molina y Vedia y Raúl Crisafio. }\end{array}$ \\
\hline
\end{tabular}




\begin{tabular}{|l|l|l|}
\hline CdP (?), a & 2002 & $\begin{array}{l}\text { Buenos Aires, Struhart y Cía. No se menciona el traductor. Intro- } \\
\text { ducción de Luis María Bandieri. Contiene el prólogo de 1963 y tres } \\
\text { Corolarios de 1931, 1938 y 1950. }\end{array}$ \\
\hline CdP 3, b & 2002 & $\begin{array}{l}\text { Buenos Aires, Struhart y Cía. Traducción de Francisco Javier Conde. } \\
\text { [El concepto de lo político] }\end{array}$ \\
\hline CdP (?) & 2006 & $\begin{array}{l}\text { Buenos Aires, Struhart y Cía. No se especifica el traductor. Contiene: } \\
\text { La época de la neutralidad. } \\
\text { [El concepto de lo político] }\end{array}$ \\
\hline CdP 3 & 2014 & $\begin{array}{l}\text { La nueva editorial virtual. Edición electrónica. Traducida de la ver- } \\
\text { sión de 1963 por Denes Martos, http://bit.ly/2MmZ2Kt }\end{array}$ \\
\hline
\end{tabular}

Fuente: Elaboración propia con base en J. E. Dotti, Carl Schmitt en Argentina, op. cit., pp. 919-929; A. De Benoist, Carl Schmitt: Internationale Bibliographie der Primär-und Sekundärliteratur, op. cit., pp. 40-41; M. L. Herrero, El nomos y lo político: la filosofía política de Carl Schmitt. Ediciones Universidad de Navarra, Edunsa, 2007, pp. 203-204.

\section{Proposiciones estructurales de El Concepto de lo Político versión de 1927}

El argumento central de El Concepto de lo Político, por capítulos, se expone a continuación en proposiciones categóricas típicas ${ }^{28}$.

Capítulo 1

Proposición [P]: Todo concepto de Estado es el que presupone el concepto de lo político.

Capítulo 2

P: Toda distinción política específica es la distinción entre amigo y enemigo.

Capítulo 3

P 1: Todos los conceptos de amigo y enemigo son aquellos que se tomarán en su sentido concreto y existencial.

P 2: Todo autentico concepto de enemigo es el que posibilita la lucha real.

P 3: Todo pueblo que no tenga la posibilidad de luchar es un pueblo que no distingue entre amigo y enemigo, por lo tanto, carece de política.

P 4: Toda guerra es la negación esencial de otro ser.

\section{Capítulo 4}

P 1: Toda unidad política es necesariamente la unidad decisiva para la agrupación de amigos y enemigos.

P 2: Todo Estado que sea una unidad decisiva es un Estado que se sustenta en su carácter político.

\footnotetext{
28 Toda proposición categórica típica responde a la siguiente estructura: cuantificador (A-E-I-O) + término sujeto + cópula (verbo ser o estar) + término predicado. Cf. I. M. Copi, Introducción a la lógica, Limusa, 2007, pp. 209-243.
} 


\section{Capítulo 5}

P 1: Todo Estado que sea una unidad esencialmente política es aquel al que le pertenece el jus belli y puede disponer abiertamente de la vida de las personas.

P 2: Todo pueblo que exista en la esfera de lo político es aquel que tiene que distinguir entre amigo y enemigo. En esto radica la esencia de su existencia política.

P 3: Todo pueblo que ya no tenga la fuerza o la voluntad para mantenerse en la esfera de lo político es un pueblo que desaparece. No desaparece lo político del mundo, tan solo un pueblo débil.

\section{Capítulo 6}

P 1: Todo pluralismo de los Estados es aquello que se deriva del rasgo conceptual de lo político.

P 2. Toda unidad política no es universal.

P 3. Ninguna guerra es aquella que se libra en nombre de la humanidad. La humanidad no es un concepto político y no le corresponde la unidad política ni el status político.

P 4: Toda Liga de las Naciones que no sea universal, sino una alianza o una coalición es aquella que puede tener importancia política. Eso no eliminaría el jus belli.

\section{Capítulo 7}

P 1: Toda vez que se quiera comprobar las teorías del Estado y las ideas políticas es vez en que se realizará sobre la base de su antropología y luego clasificarlas, presuponiendo, consciente o inconscientemente, un hombre "malo por naturaleza" o "bueno por naturaleza".

P 2: Toda vez que la esfera de lo político se determine por la posibilidad real de un enemigo es momento en que las representaciones y pensamientos políticos no pueden tomar como punto de partida un optimismo antropológico.

P 3: Todo pensamiento político, así como todo instinto político es aquello que se prueba en la posibilidad real de la distinción entre amigo y enemigo.

\section{Capítulo 8}

P 1: El liberalismo del último siglo es aquel que ha transformado y desnaturalizado de forma singular y sistemática todas las nociones estatales y políticas.

P 2: Todo pensamiento liberal es aquel que elude o ignora al Estado y la política de modo extremadamente sistemático y se mueve típicamente entre la ética y la economía y desde estos dos extremos tratan de disolver lo político.

P 3: Todo pathos liberal es aquel que se dirige contra cualquier tipo de empleo de violencia y falta de libertad. Dando como resultado un sistema de conceptos desmilitarizados y despolitizados.

P 4: Toda referencia al concepto político de "lucha" en el pensamiento liberal es aquella que deviene, por el lado económico en competencia y por el lado "espiritual" en discusión. En lugar de establecer una clara distinción entre la "guerra" y "paz", surge la eterna competencia y la eterna discusión. 


\section{El Concepto de lo Político [1927]}

\section{1}

El concepto de Estado presupone el concepto de lo político. El Estado es el status político de un pueblo. Esto tan sólo es una primera aproximación, más no una determinación conceptual del Estado. Cosa que tampoco es necesaria, ya que lo que interesa aquí es la esencia de lo político. Por el momento podemos dejar en suspenso cuál es la esencia del Estado, si es una máquina o un organismo, una persona o una institución, una sociedad o una comunidad, una empresa, una colmena o tal vez una "serie básica de procedimientos". Todas estas definiciones e imágenes anticipan demasiado en lo que se refiere a la interpretación, el sentido, la ilustración y la construcción, y, por lo tanto, no pueden constituir un punto de partida adecuado para una exposición sencilla y elemental. El Estado, de acuerdo al sentido del término y a su fenómeno es un particular modo de estar [Status] de un pueblo. De momento no cabe decir más. Los rasgos de esta representación -Status y Pueblo- adquieren su sentido mediante la característica adicional de lo político y se vuelven incomprensibles si la esencia de lo político no se entiende adecuadamente.

Es raro encontrar una definición clara de lo político. Casi siempre, la palabra se utiliza negativamente, en oposición a otros conceptos diferentes, en antítesis como política y economía, política y moral, política y derecho, y a su vez, en el ámbito del derecho, entre política y derecho civil ${ }^{1}$. Por medio de estas contraposiciones negativas, a menudo polémicas, se puede llegar a señalar algo suficientemente claro, dependiendo del contexto, pero esto no equivale todavía a una determinación de lo específico. En general, lo "político" suele relacionarse de alguna manera con lo "estatal" o por lo menos referirse al Estado ${ }^{2}$. Entonces, el Estado se muestra como algo político y lo político como algo estatal, obviamente un círculo vicioso insatisfactorio. En la literatura jurídica especializada se encuentra numerosas aproximaciones de lo político, pero sólo se pueden entender a partir del interés práctico-técnico de las sentencias de casos individuales. Existe una jurisprudencia y literatura sobre el concepto de "asociación política" o de "reunión política" en el derecho de asociación ${ }^{3}$.

La contraposición entre el derecho y la política se mezcló fácilmente con la oposición entre el derecho civil y el derecho público, por ejemplo, Bluntschli, Allgemeines Staatsrecht I (1868), p. 219: "La propiedad es un concepto del derecho privado, no un concepto político". El significado actual de esta antítesis apareció especialmente en el debate sobre la expropiación del patrimonio de las castas [Fürstenhäuser] que antes gobernaban en Alemania en 1925 y 1926; menciónese como ejemplo la siguiente frase del discurso del diputado Dietrich (Sesión del Reichstag del 2 de diciembre de 1925, informe 4717): "Somos de la opinión de que, en general, no se trata aquí no de cuestiones del derecho privado, sino únicamente de cuestiones políticas” (¡Muy bien! de los demócratas y la izquierda).

2 También en las definiciones de lo político que utilizan el concepto del "poder" como característica decisiva, este poder aparece, la mayoría de la veces, como poder estatal, por ejemplo en Max Weber: la aspiración de participación del poder o influencia en la distribución del poder, ya sea entre Estados, ya sea dentro del Estado entre los grupos humanos que éste abarca; o bien: "El liderazgo y la influencia de una asociación política, o sea, hoy: de un Estado" (Politik als Beruf, [Política como profesión] 2a ed., 1926, p. 7); [Gesammelte politische Schriften, (Escritos completos de política) $3^{\mathrm{a}}$ ed., 1971, p 505]. Presentación de Ed. Spranger de "Machtmenschen" [El hombre de poder] (Lebensformen [Formas de vida], II. Sec. 2., cap. 5 [3 $3^{\mathrm{a}}$ ed., 1922, pp. 188-210] se adentran tan profundamente en la psicología individual de la aspiración privada al poder, que lo específicamente político, frecuentemente, pierde importancia. Pero las características específicas de la esfera política también se afirman aquí, cf. abajo, nota 11 .

3 Según el § 3, parte 1 del Deutsches Reichsvereinsgesetz [Ley de asociación del Reich alemán] del 19 de abril de 1908 , es una asociación política "cualquier asociación que tiene como objetivo influir en las cuestiones 
Además, la práctica del derecho administrativo francés ha intentado establecer un concepto del "móvil político" (mobile politique) con ayuda de los cuales, los actos del gobierno (actes de gouvernement) deben distinguirse de los actos administrativos y ser retirados del control de los tribunales administrativos ${ }^{3 a}$. Tales conceptos, derivados de las necesidades de la práctica jurídica, no pretenden otra cosa que proporcionar una justificación práctica para delimitar los diversos supuestos de hecho que se producen en la práctica jurídica, pero su objetivo no es una definición general de lo político. De ahí que surgen con referencia al Estado o a lo estatal en general y pueden presuponer al Estado y las instituciones como grandezas conocidas. Pero también, las determinaciones conceptuales generales de lo político que se refieren al Estado son comprensibles y además científicamente justificadas, siempre y cuando el Estado pueda ser considerado como una grandeza clara y determinada, mientras que hoy, tanto el concepto de Estado como su realidad efectiva, se han convertido en un problema.

Una determinación conceptual de lo político se puede lograr solamente a través del descubrimiento y verificación de las categorías políticas específicas. De hecho, lo político es independiente, como una zona separada junto a otros ámbitos relativamente autónomos del pensar y del quehacer humano, en particular, con lo moral, lo estético y lo económico, etc., cuya enumeración exhaustiva no es necesaria aquí. Por lo tanto, lo político tiene que encontrarse en sus propias distinciones, relativamente autónomas, relativamente últimas, a las cuales pueda reconducirse todo cuanto sea acción política en un sentido específico. Supongamos que, en el ámbito moral, la distinción es la del bien y el mal; en lo estético, la de lo bello y lo feo; en lo económico, la de lo beneficioso o lo perjudicial, o por ejemplo la de lo rentable y lo no rentable. Entonces, surge la pregunta de si en el campo de lo político existe alguna distinción especial, independiente y que se imponga por sí misma, y si existe, ¿cuál es?

La distinción política específica, a la que pueden remitirse las acciones y motivos políticos, es la distinción entre amigo y enemigo. Al ámbito de lo político le corres-

políticas". Las cuestiones políticas son, entonces, en la práctica, llamadas habitualmente como cuestiones que se refieren a la conservación o modificación de la organización estatal, o a la influencia sobre las funciones del Estado o a las corporaciones de derecho público integradas en él. En tales y parecidas descripciones, las cuestiones políticas, estatales y públicas, pasan unas sobre otras. Hasta 1906 (Juicio del Kammergericht del 12 de febrero de 1906, Johow, vol. 31 C. 32-24) la práctica, en Prusia, trató también bajo el decreto del 13 de marzo de 1850 ([Preußische Gesetzessammlung], p. 277) toda actividad de asociaciones eclesiásticas y religiosas sin calidad de corporación, incluso las horas de meditación religiosa, como influencia sobre cuestiones públicas o discusión de tales cuestiones; sobre el desarrollo de esta práctica, cf. H. Geffcken, "Öffentliche Angelegenheit, politischer Gegenstand und politischer Verein nach preußischem Recht”, Festschrift für E. Friedberg, 1908, pp. 287 y ss.

3a Jèze, Les principes généraux du droit administratif 1, 3.a ed., 1925, p. 392, para quien toda esta distinción es solamente la "opportunité politique". Además: R. Alibert, Le controle jurisdictionnelde l'administration, Paris, 1926, pp. 70 y ss. Literatura adicional en Smend, Die politische Gewalt im Verfassungsstaat und das Problem der Staatsform, Festschrift für Kahl, Tübingen, 1923, p. 16; Smend determina el "círculo de la política" [Kreis der Politik] como el área en la que el Estado prevalece y se determina así mismo su esencia. También permanece en el círculo del gobierno y la política. La distinción entre "actes de gouvernement" y "actes de simple administration" obtuvo otro significado cuando, en junio de 1851, en la Asamblea Nacional francesa, se debatió la responsabilidad parlamentaria del presidente de la República, y el presidente quiso asumir, el mismo, la responsabilidad realmente politica; es decir, la de los actos de gobierno, cfr. Esmein-Nèzard, Droit Constitutionnel 7.a ed. I, p. 234. Distinciones análogas en el debate de las competencias de un "Geschäftsministerium" según el art. 52, parte 2 de la Constitución Prusiana de 1920 cf. Arch. Off. Rechts, 9. Bd. (1925), pp. 211ss., especialmente p. 223. 
ponde los opuestos relativamente autónomos de otras áreas: la del bien y del mal en lo moral, la de belleza y fealdad en lo estético, etc. Es autónoma, es decir, que no se derivan ni se remiten a alguna de estas u otras oposiciones. La contraposición entre el bien y el mal no puede ser identificada sin más, con la de belleza y fealdad o con lo beneficioso y perjudicial, ni ser reducida inmediatamente a ellas, mucho menos la oposición entre amigo y enemigo debe confundirse o mezclarse con una de esas contraposiciones. La distinción entre amigo y enemigo puede existir en la teoría y en la práctica sin que, al mismo tiempo, se apliquen distinciones morales, estéticas, económicas y demás. El enemigo político no necesita ser moralmente malo ni estéticamente feo; no debe mostrarse como un competidor económico e incluso puede ser beneficioso hacer negocios con él. Pero sigue siendo el otro, un extranjero, y para determinar su esencia basta con que sea, en un sentido particularmente intenso, existencialmente distinto [un otro] y un extraño, de tal modo que, en caso de conflicto, representa la negación del propio modo de existencia y por eso es rechazado y combatido para preservar la propia forma esencial de vida. Desde una perspectiva psicológica es fácil considerarlo, al enemigo, como malvado y despreciable [häßlich], porque lo político, como cualquier ámbito autónomo de la vida humana, prefiere apoyarse en las distinciones de otras áreas. Esto no cambia la autonomía de los opuestos específicos. De hecho, también se puede invertir: lo que es moralmente malo, estéticamente feo o económicamente perjudicial no tiene por qué ser enemigo; ni tampoco lo que es moralmente bueno, estéticamente hermoso y económicamente rentable se convierte, por esta sola razón, en amigo, en sentido específico; es decir, político del término. La objetividad e independencia, propias del ser de lo político, se muestran en la posibilidad de separar la oposición específica de amigo-enemigo de otras distinciones y concebirlas como algo autónomo.

\section{3}

Los conceptos de amigo y enemigo deben tomarse en su sentido concreto y existencial, no como metáforas o símbolos; sin mezclarlos ni atenuarlos por medio de representaciones económicas, morales u otro tipo, ni psicológicamente como expresión de sentimientos y tendencias particulares. No son contraposiciones normativas o "espirituales". El liberalismo (como se mostrará más adelante en forma detallada) transformó al enemigo desde el punto de vista económico en un competidor y desde el punto de vista ético en un adversario de la discusión. En el área económica no existen enemigos, sino únicamente competidores; en un mundo moralizado y reducido a la eticidad solo hay oponentes de la discusión. Pero el enemigo es otra cosa. Si se considera reprochable o no y quizás se encuentre un resto atávico de épocas bárbaras en la cual, los seres humanos todavía se diferencian en función de amigos y enemigos, o si se espera que algún día esa distinción desaparezca de la tierra, o si es bueno y correcto por razones educativas o tácticas fingir que no hay más enemigos, todo esto no se toma en cuenta aquí. No se trata de ficciones o normatividades, sino de la realidad óntica [seinsmäßige] y de la posibilidad real de esta distinción. Se puede compartir o no las esperanzas y aspiraciones educativas, pero lo que no se puede negar racionalmente es que los pueblos se pueden agrupar entre amigos y enemigos y que esta oposición, hasta hoy, está dada como una posibilidad real para cada pueblo políticamente existente.

El enemigo no es el competidor o el adversario en general. El enemigo tampoco es el adversario privado al que se detesta. El enemigo es solamente un grupo de hom- 
bres que luchan eventualmente, es decir, de acuerdo a una posibilidad real frente a otros. El enemigo es únicamente el enemigo público, porque todo lo que se relaciona con un grupo de personas y en particular con todo un pueblo se vuelve público. El

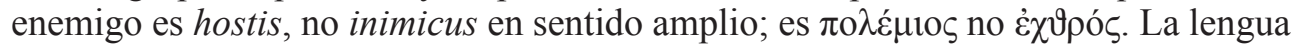
alemana, como también otras, no distingue entre "enemigo" privado y "enemigo" político, de tal manera que son posibles muchos malentendidos y alteraciones. El conocido pasaje, "amad a vuestros enemigos" (Mt. 5, 44 y Lc. 6, 27), dice: "diligite

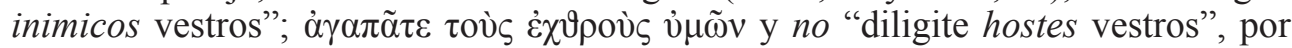
lo tanto, no se habla del enemigo político. El enemigo, en sentido político, no tiene por qué ser odiado personalmente, si tiene algún sentido amar a su "enemigo", es decir, a su adversario, es solamente en la esfera privada. Ese pasaje alude tan poco a la contraposición política que anula las contradicciones entre el bien y el mal o lo bello y lo feo. Esto no quiere decir, en absoluto, que se deba amar a los enemigos de su pueblo y apoyarlos contra el suyo.

Al auténtico concepto de enemigo le pertenece la posibilidad real de una lucha. Con esta sentencia uno debe prescindir de todas las modificaciones fortuitas de la técnica de la guerra y de las armas sujetas al desarrollo histórico. La guerra es una lucha armada entre pueblos. Lo esencial del concepto de arma es que es un instrumento para matar físicamente a los seres humanos. Al igual que la palabra "enemigo", el término "lucha" se han de entender aquí, en su sentido originario y existencial. Esto no significa una competencia, ni una lucha [Kampf] "espiritual” de la discusión, ni una "lucha" [Ringen] simbólica que, en última instancia, cada persona lleva a cabo de alguna manera, aunque sea por inercia. Los conceptos de amigo, enemigo y lucha adquieren su verdadero significado, debido a que tienen y mantienen particular referencia, especialmente, con la posibilidad real de matar físicamente. La guerra se deriva de la enemistad, porque es la negación esencial de otro ser. La guerra es simplemente la realización extrema de la enemistad. No necesita ser cotidiana ni normal, ni siquiera ser percibida como algo ideal, pero debe permanecer como una posibilidad real, siempre y cuando el concepto de enemigo tenga sentido.

Es evidente que no todos los detalles de la existencia política son una guerra sangrienta ni cada acción política tiene como objetivo una futura acción militar, ni que cada pueblo se enfrenta constantemente ante la alternativa del amigo o enemigo; y que lo políticamente correcto puede ser, precisamente, evitar la guerra. La definición que se da aquí de lo político no es militarista ni imperialista, como tampoco pacifista. No se trata de presentar la guerra como "ideal social", porque no es ni "social" ni "ideal". La distinción entre amigo y enemigo tampoco significa que un determinado pueblo tenga que ser eternamente amigo o enemigo de otro. Desde luego, la neutralidad siempre puede ser posible y políticamente adecuada. El concepto de neutralidad, como todo concepto político, se encuentra también bajo la última condición: la posibilidad real de la agrupación entre amigos y enemigos, y si en la tierra existiera solamente la neutralidad, entonces no sólo se habría terminado la guerra, sino también la neutralidad, al igual que con cualquier política, incluso con la política que trate de evitar la guerra, si se elimina la posibilidad real de la guerra. Lo determinante es siempre la posibilidad de este caso decisivo, de la guerra real, y la decisión sobre ella, si existe o no. Que este caso ocurra excepcionalmente no anula su carácter determinante, sino que ante todo lo fundamenta. Aunque las guerras ya no son tan numerosas y cotidianas como en el pasado, han aumentado abrumadora y completamente su fuerza, igual o quizás más de lo que han disminuido en número y 
frecuencia. Incluso hoy, el caso de guerra es el "caso de emergencia". Se puede decir que aquí, como en otros, el caso excepcional tiene un significado particularmente decisivo. Porque sólo en la lucha real se muestra la consecuencia última de la agrupación política de amigos y enemigos. A partir de esta posibilidad extrema, la vida de las personas adquiere su tensión específicamente política.

Un mundo sin la posibilidad de una lucha sería un mundo sin la distinción entre amigos y enemigos y, por lo tanto, un mundo sin política. Puede haber en ella varias contradicciones excesivamente violentas, pero no tendría sentido una oposición sobre la que se puede exigir a los hombres el sacrificio de sus vidas y sobre la facultad que tengan algunos de ellos para derramar sangre y matar a otros hombres. También aquí, la definición de lo político no depende si se desea, como estado ideal, un mundo sin política. El concepto de lo político sólo puede determinarse únicamente por la referencia con la posibilidad real de la agrupación de amigo y enemigo, independientemente del resultado de la valoración religiosa, moral, estética o económica de lo político. La guerra como el medio político más extremo, revela la posibilidad de la distinción entre amigo y enemigo que subyace a toda representación política y, por lo tanto, sólo tiene sentido mientras esta distinción pueda darse realmente en la humanidad o tan solo como una posibilidad real. La guerra no es "la continuación de la política por otros medios", como dice la famosa definición ${ }^{4}$. Por supuesto, tampoco es el objetivo y el propósito de la política, sino la condición de que siempre existe como una posibilidad real que determina la acción humana de forma particular y le otorga un sentido específicamente político.

Una guerra librada por motivos estrictamente religiosos, morales o económicos es absurda. De las contraposiciones específicas de los ámbitos de la vida humana no puede inferirse la agrupación entre amigos y enemigos y tampoco una guerra. Una guerra no necesita ser alguna cosa piadosa, ni algo moralmente bueno, ni algo rentable; hoy, probablemente, no es nada de eso. Esta simple percepción se confunde, debido a que las contraposiciones religiosas, morales y otras, se utilizan con fines políticos, para propiciar la agrupación de combate decisivo de acuerdo al amigo o enemigo. Sin embargo, si resulta esta agrupación de combate, entonces la contraposición decisiva ya no es únicamente religiosa, moral o económica, sino política. $\mathrm{La}$ pregunta es, entonces, si esta agrupación de amigos y enemigos existe o no como posibilidad real, independientemente de qué motivos humanos sean lo suficientemente fuertes para provocar esta agrupación. Nada escapa a esta consecuencia de lo político. Si la oposición pacifista contra la guerra fuera tan fuerte que pudiera impulsar al pueblo a una guerra contra los no-pacifistas, a una "guerra contra la

$4 \quad$ Clausewitz, Vom Kriege III, Berlín, 1834, p. 140, dice: "La guerra no es más que una continuación de las relaciones políticas con la injerencia de otros medios". La guerra es, para él, un "simple instrumento de la política". Sin embargo, la guerra, es también eso; pero su significado para el conocimiento de la esencia de lo político todavía no se ha agotado. Mirándolo detenidamente, por otra parte, para Clausewitz, la guerra uno es uno más entre muchos instrumentos, sino la "última ratio" de la agrupación de amigo y enemigo. La guerra tiene su propia "gramática" (es decir, un procedimiento especial técnico-militar), pero ninguna "lógica propia". Esto sólo se puede obtener, concretamente, de los conceptos de amigo y enemigo, y este es el núcleo de todo lo político que se muestra en la frase página 141: "Si la guerra pertenece a la política, entonces ella adoptará su carácter. Tan pronto como se vuelva grandiosa y poderosa, así será la guerra, y esto puede incrementarse hasta el nivel donde la guerra alcance su forma absoluta". Además, otras numerosas frases demuestran hasta qué punto cada consideración específicamente política se basa sobre esas categorías políticas, especialmente, por ejemplo, las declaraciones relativas a las guerras de coalición y alianzas, op. cit., pp. 135 y ss.; cf. también H. Rothfels, Carl von Clausewitz, Politik und Krieg, Eine Ideengeschichtliche Studie, Berlín, 1920, p. 198, 202. 
guerra", entonces demostraría que realmente tiene el poder político, porque es lo suficientemente fuerte como para agrupar a los hombres en amigos y enemigos. Si la voluntad de impedir una guerra es tan fuerte que ya no se intimida ante la misma guerra, entonces se ha convertido en un motivo político, es decir, que, aunque sólo sea como una eventualidad extrema se afirma la guerra y el sentido de la guerra. En la actualidad, esto parece ser un modo particularmente prometedor de provocar la guerra. Entonces, la guerra se desarrolla como "la última y definitiva guerra de la humanidad". Tales guerras son necesariamente intensas e inhumanas, porque van más allá de lo político, tienden a despreciar al enemigo por medio de categorías morales y otras, convirtiéndolo, al mismo tiempo, en un monstruo inhumano que no sólo debe ser repelido, sino definitivamente aniquilado, es decir, que ni siquiera el enemigo es tratado objetivamente. La posibilidad de tales guerras se muestra de un modo particularmente claro, que la guerra sigue existiendo como una posibilidad real y es lo único que importa para la distinción entre amigos y enemigos y para el conocimiento de lo político.

\section{4}

Todo antagonismo religioso, moral, económico, étnico u otro, se transforma en una oposición política si es lo suficientemente fuerte como para agrupar de manera efectiva a las personas entre amigos y enemigos. Lo político no se encuentra en la lucha en sí, que tiene sus propias leyes técnicas, psicológicas y militares, sino, como ya mencioné, en un comportamiento determinado por esa posibilidad real, siendo plenamente consciente de su propia situación y en la capacidad de distinguir al amigo y enemigo. Una comunidad religiosa que provoque guerras, ya sea, contra miembros de otras comunidades religiosas u otro tipo de guerras es una unidad política más que una comunidad religiosa. Si es capaz de impedir la guerra por medio de una prohibición a sus miembros, es decir, negando completamente la naturaleza de enemigo a un adversario, entonces también es una fuerza política, aunque sólo sea en sentido negativo, porque tiene la posibilidad de influir en el proceso decisivo. Lo mismo se aplica a una asociación de personas basada en un fundamento económico, por ejemplo, para un sindicato. También una "clase", en el sentido marxista del término, deja de ser algo puramente económico y se convierte en una fuerza política cuando llega el momento decisivo, es decir, cuando toma en serio la lucha de clases y trata al adversario de clase [Klassengegner] como a un verdadero enemigo y lo combate. La verdadera lucha no se lleva a cabo, necesariamente, según leyes económicas, sino que, además de la técnica de combate en el estricto sentido técnico, tiene sus necesidades y orientaciones políticas. Si el proletariado, dentro de un Estado, se toma el poder político, entonces habrá surgido un estado proletario, que no es otra cosa que una entidad política, como un Estado nacional o un Estado de funcionarios [Beamtenstaat] o cualquier otra categoría de Estado. Si pudiéramos agrupar a toda la humanidad como amigos y enemigos, en Estados proletarios y Estados capitalistas, según la oposición de burgueses y proletarios, y si desaparecen en ellas todas las demás agrupaciones de amigos y enemigos, entonces se hace evidente la realidad misma de lo político que al principio solo conservaban nociones económicas. Si el poder político que tiene un grupo [Klasse] dentro de un pueblo es lo suficiente para impedir que alguien provoque la guerra externamente, pero no tiene la capacidad o la voluntad para asumir el poder del Estado y si es necesario para hacer la guerra, entonces la unidad política se ha disuelto. 
Lo político puede sacar su fuerza de los ámbitos más diversos de la vida humana, de los antagonismos religiosos, económicos y morales. Pero la agrupación real de amigos y enemigos es tan fuerte y decisiva en sí mismo [seinsmäßig] que la contraposición no política, en el mismo instante en que dirige esta agrupación abandona sus criterios anteriores y se somete a las condiciones y consecuencias completamente nuevas de lo político. Lo político siempre determina la agrupación que se orienta a partir del caso de emergencia. Por lo tanto, la unidad política, siempre que ella exista, es la unidad determinante y "soberana" en el sentido de que la decisión sobre el caso de emergencia, incluso si el caso es excepcional, permanece con ella. Por eso, siempre es la agrupación determinante. Aquí, el término soberanía tiene un buen significado, igual que la palabra unidad. Esto no significa, en absoluto, que cada detalle de la existencia de las personas, que pertenecen a una unidad política debe estar determinado y comandado por lo político. Puede ser que las cuestiones económicas sean más fuertes que cualquier otra cosa que los líderes políticos quieran, es decir, el gobierno, precisamente, en las convicciones religiosas, el poder del Estado encuentra fácilmente un límite. Lo que importa es el caso de conflicto. Si las fuerzas opositoras económicas o religiosas son tan fuertes que determinan por sí mismas la decisión sobre el caso de emergencia, entonces se han convertido en la nueva sustancia de la unidad política. Si no son lo suficientemente fuertes como para evitar una guerra decidida en contra de sus propios intereses, demuestra que no han alcanzado el punto decisivo de lo político. Si son lo suficientemente fuertes como para impedir una guerra deseada por los líderes políticos, contra sus intereses o motivos, pero no lo suficientemente fuertes como para determinar, por sí mismos, una guerra, entonces no existe una grandeza política homogénea. Como sea que se comporten, debido a la orientación que tiene el posible caso de emergencia, de un combate efectivo contra un enemigo efectivo, necesariamente la unidad política es: o la unidad determinante para la agrupación de amigos o enemigos, y en este sentido soberana (no en cualquier sentido absoluto), o definitivamente no existe.

Cuando se reconoció el gran significado político que desempeñan dentro del Estado las asociaciones económicas y, en particular el crecimiento de los sindicatos, contra cuyo poder económico, la huelga y las leyes del Estado eran considerablemente impotentes, se proclamó, algo precipitado, la muerte y el fin del Estado. Esto, por lo que veo, como doctrina propiamente dicha, ocurrió desde 1906 y 1907 con los sindicalistas franceses ${ }^{5}$. De los teóricos del Estado que pertenecen a esta tendencia, Duguit es el más conocido. Desde 1901 ha intentado refutar el concepto de soberanía y la idea de la unidad personal del Estado, con algunos argumentos precisos contra una metafísica del Estado acrítico, pero en esencia pierde el verdadero sentido de la

"Cette chose énorme... la mort de cet être fantastique, prodigieux, qui a tenu dans l'histoire une place si colossale: l'Etat est mort" (E. Berth, cuyas ideas proceden de Georges Sorel, en Le mouvement socialiste, octubre, 1907, p. 314). Léon Duguit cita este pasaje en sus conferencias sobre Le droit social, le droit individuel et la transformation de L'Etat, 1.a ed., 1908; se limitó a decir que el Estado soberano y pensado como persona estaba muerto o a punto de morir (p. 150: L'Etat personnel et souverain est mort ou sur le point de mourir). En la obra de Duguit, L'Etat, [El título completo es: L'Etat, le droit objectif et la loi positive], Paris 1901, no se encuentra todavía este tipo frases, a pesar de que la crítica al concepto de soberanía es, incluso, la misma. Otros ejemplos interesantes de este diagnóstico sindicalista del Estado moderno[heutigen] en Esmein, Droit constitutionnel (7.a ed. de Nézard), 1921,1, pp. 55 y ss. La doctrina sindicalista debe diferenciarse también, con respecto a su diagnóstico del Estado, de la construcción marxista. Para los marxistas el Estado no está muerto o a punto de morir, de hecho, es un medio necesario, y por el momento aún real, para conseguir la sociedad sin clases y, por tanto, sin Estado. 
soberanía que se acabó de mencionar. Lo mismo se puede decir de la teoría del estado más interesante de la última década, de la teoría pluralista del Estado de Harold J. Laski ${ }^{6}$. Su pluralismo consiste en negar la unidad soberana del Estado, es decir, la unidad política, y otra vez insistir que cada persona vive en numerosas asociaciones: es miembro de una comunidad religiosa, de un sindicato, de un club deportivo y de otras "asociaciones" que, en cada caso, lo determinan con variable intensidad sin que se pueda decir que alguna de estas asociaciones es realmente decisiva y soberana. Al contrario, las diversas "asociaciones", cada una en áreas diferentes, pueden demostrar ser la más fuerte. Es posible, por ejemplo, que los miembros de un sindicato, si emiten la consigna [Parole] de no asistir a la iglesia, a pesar de eso irían, pero al mismo tiempo se negarían a obedecer la exhortación promulgada por la iglesia de salir del sindicato. El proceso histórico que Laski cita con especial preferencia y que aparentemente le causó una fuerte impresión es la "guerra cultural" [Kulturkampf] de Bismarck contra la Iglesia romana. Laski debe probar que incluso un Estado con la fuerza inquebrantable del Imperio de Bismarck no fue soberano ni omnipotente. Tampoco el Estado es omnipotente en el campo económico. Todo esto es indudablemente cierto y las expresiones sobre la "omnipotencia" del Estado no son sino expresiones superficiales de los juristas. Pero esto todavía no responde a la pregunta de qué "unidad social" (si me permiten tomar aquí el impreciso concepto liberal de lo "social") decide el caso de conflicto y determina la agrupación decisiva de amigos y enemigos. Ni una iglesia, ni un sindicato, habría prohibido o impedido una guerra que el Imperio alemán, bajo Bismarck, decidió. Desde luego, Bismarck no podía declararle la guerra al Papa, pero solamente porque el Papa no tenía jus belli. En cualquier caso, no habría sido posible imaginar una instancia que se hubiera querido o podido oponerse a una decisión del Gobierno alemán de entonces sobre un caso de emergencia, sin convertirse, al mismo tiempo, en enemigos políticos y encontrarse con todas las consecuencias de este concepto. Esto es suficiente para establecer un concepto racional de soberanía y unidad. La unidad política es, por su propia esencia, la unidad determinante, independientemente de qué motivos extraiga sus últimas fuerzas psicológicas. Existe o no existe. Si existe es la unidad suprema, es decir, la que determina en el caso decisivo.

Que el Estado sea una unidad y que además sea la unidad decisiva, reside en su carácter político. Una teoría pluralista que niega esta unidad y que coloca una asociación política junto a otras, por ejemplo, junto a asociaciones religiosas o económicas, no está en condiciones de responder a la pregunta sobre el contenido específico de lo político. En ninguno de los muchos libros de Laski se encontrará una definición precisa de lo político, aunque siempre se habla de estado, política, soberanía y "government". El Estado se transforma simplemente en una asociación que compite con otras asociaciones. Llega a ser una sociedad junto y entre muchas sociedades que existen dentro o fuera del Estado. Este es exactamente el "pluralismo" de esta teoría del Estado. Por supuesto, la antigua "superioridad" del Estado, su "soberanía" frente a la sociedad y su "monopolio" de la unidad máxima ha sido suprimida. Sin embargo, si se examina cuidadosamente, sigue siendo poco claro en Laski lo que debe ser, a partir de ahora, el "Estado". A veces, se parece a la vieja manera liberal, como simple servidora de la sociedad, determinada esencialmente

Studies in the Problem of Sovereignty, 1917; Authority in the Modern State, 1919 [The] Foundation of Sovereignty, 1921, A Grammar of Politics, 1925. 
por la economía y, a veces, pluralista, como una especie particular de la sociedad, es decir, como una asociación junto a otras asociaciones. Pero, sobre todo, lo que debería quedar claro es por qué razón los hombres crean, junto a las asociaciones religiosas, económicas y otras asociaciones, también asociaciones políticas, y cuál es el objetivo específicamente político de estas asociaciones. Aquí se encuentra una ambigüedad fundamental, no se puede distinguir una línea de pensamiento clara y simple. Esta teoría pluralista del Estado es, sobre todo, pluralista, es decir, que no tiene un centro homogéneo, sino que extrae sus motivos intelectuales desde los más diversos círculos conceptuales (religión, economía, liberalismo, socialismo, etc.) e ignora el concepto central de toda teoría del Estado, lo político. En realidad, no existe una "sociedad" o "asociación política" sólo existe una unidad política, una comunidad política. La posibilidad real de agrupar entre amigos y enemigos es suficiente para crear una unidad decisiva, más allá de lo simplemente social-asociativo [Gesellschaftlich-Assoziative], que es algo específicamente diferente y determinante frente a las demás asociaciones ${ }^{7}$. Si esta unidad se suprime, también desaparece lo político en sí mismo. Mientras la esencia de lo político no sea reconocida o no sea observada es posible colocar una "asociación" política pluralista junto a una religiosa, cultural, económica y otras asociaciones, y dejar que compitan con ella. Del concepto de lo político surgen consecuencias pluralistas sin destruir lo político en sí mismo con la unidad, como mostraré más adelante, pero no en el sentido de que dentro de la unidad política y en lugar de la agrupación decisiva de amigos y enemigos pueda surgir un pluralismo.

\section{5}

Al Estado, como una unidad esencialmente política, le pertenece el jus belli, es decir, la posibilidad real de determinar, en el momento dado y en virtud de su decisión propia, quién es el enemigo y combatirlo. Con qué medios técnicos se lleve a cabo la guerra, qué organización militar existe, qué tan grande son las posibilidades de ganarla, aquí es indiferente, siempre y cuando el pueblo que conforma la unidad política esté dispuesto a luchar por su existencia y por su independencia, decidiendo por sí mismo, en qué consiste su independencia y su libertad. El desarrollo de la técnica militar parece conducir, a que, tal vez, permanezcan tan sólo los pueblos cuyo poder industrial les permita hacer la guerra con probabilidades de éxito, mientras que los pueblos más pequeños renunciarán voluntariamente o por la fuerza al jus belli, si no logran conservar su independencia por medio de una legítima política de alianzas. Con este desarrollo no se ha demostrado que la guerra, el Estado y la política hayan terminado completamente. Cada modificación y revolución de la historia y el desarrollo ha producido nuevas formas y nuevas dimensiones de la agrupación política y ha destruido las viejas estructuras políticas.

El Estado, como unidad política determinante, ha concentrado en sí un enorme poder: la posibilidad de hacer la guerra y, de ese modo, disponer abiertamente de la vida de las personas. Porque el jus belli contiene esa disposición, lo que significa una doble posibilidad: exigir a los miembros de su propio pueblo la disposición para morir y matar, y para matar a las personas que están del lado-enemigo.

Podemos decir que, la sociedad [Gesellschaft] que existió hasta entonces, el día de la movilización, se transformó en una comunidad [Gemeinschaft], Lederer, Archivo para la ciencia y política social [Archiv für Sozialwissenschaft und Sozialpolitik] 39 (1915), p. 349. 
La facultad de disponer de la vida y la muerte de las personas, por medio de una sentencia penal [Strafurteils], el jus vitae ac necis, también puede deberse a otra asociación existente dentro de la unidad política, por ejemplo, la familia o al padre de familia, pero nunca al "jus belli", mientras que la unidad política exista como tal. Además, el derecho a la venganza de sangre entre familias o clases debería ser suspendido durante una guerra, si es que existe realmente una unidad política. Una asociación que quisiese renunciar a estas consecuencias del jus belli no sería una asociación política, porque renunciaría a la posibilidad de decidir definitivamente quién considera y trata como enemigo. Debido a este poder, disponer sobre la vida física de las personas, se eleva la comunidad política sobre cualquier otro tipo de comunidad o sociedad. Siempre que exista la unidad, dentro de la comunidad, las subestructuras pueden volver a tener poder, pero no como un jus belli independiente.

Una comunidad religiosa, una iglesia, puede tal vez exigir a sus miembros que mueran por su fe y que se soporten el martirio, pero sólo por la salvación de su alma, no por la comunidad religiosa como tal. En una sociedad determinada por lo económico, cuyo sistema, es decir, su funcionamiento calculable ocurre en el ámbito de las categorías económicas, no se puede, bajo ningún punto de vista imaginable, exigir a ningún miembro de la sociedad que sacrifique su vida en beneficio del funcionamiento ininterrumpido. Justificar este tipo de exigencias con objetivos económicos sería una contradicción frente a los principios individualista de la sociedad y que nunca se podría justificar a partir de normas e ideales económicos. Cada persona puede morir voluntariamente por lo que quiera. Una sociedad que funciona económicamente también encontrará los medios para poner a un perturbador fuera de su sistema y convertirlo en alguien inofensivo de una manera no-violenta, "pacífica", o sea, concretamente hablando, dejarlo morir de hambre si es necesario. Pero no hay ningún programa, ninguna norma y ningún propósito, por muy correcto, racional y extraordinario que sea, de cuyo contenido, pueda surgir el derecho a disponer sobre vida física de otras personas. Pedir seriamente a las personas que maten a otros hombres y estén dispuestos a morir por el bienestar del comercio y la industria de los sobrevivientes o para incrementar la capacidad de consumo de los nietos, es aterrador y disparatado. Maldecir la guerra como el asesinato de personas y después pedir que los hombres hagan la guerra, que maten y se dejen matar en ella para que "nunca más haya otra guerra" es un engaño manifiesto. La guerra, la disposición para morir de los hombres que combaten, la muerte física de otros hombres que se encuentran del lado enemigo, todo esto no tiene un significado normativo, sino solamente un sentido existencial y, de hecho, solamente en la realidad de una situación de guerra real contra un enemigo real, no en cualquier programa o normatividad ideal. No hay ningún propósito racional, ninguna norma legítima, ningún programa ideal, ninguna legitimidad o legalidad que pueda justificar que los hombres se maten entre sí por ello. Si semejante destrucción física de la vida humana no ocurre por la afirmación existencial de la propia forma de existencia frente a una negación existencial similar, entonces no se puede simplemente justificar. Ni siquiera con normas éticas y jurídicas se puede justificar la guerra. Si hay verdaderos enemigos en el sentido existencial, como se quiere decir aquí, entonces tiene sentido, pero sólo sentido político, en caso de ser necesario defenderse físicamente y luchar con ellos. Esto no es legitimización o justificación, más bien tiene un sentido puramente existencial. 
Que la justicia no pertenece al concepto de la guerra ha sido generalmente reconocido desde Grotius ${ }^{8}$. Las estructuras [Konstruktionen] que exigen una guerra justa, normalmente vuelven a tener un propósito político. Pedir a un pueblo políticamente unido que haga la guerra sólo por una causa justa es, o bien, algo completamente obvio, si eso significa que solamente se puede hacer la guerra contra un enemigo verdadero; o bien, se oculta detrás la voluntad política la disposición de poner en otras manos el jus belli y encontrar normas de justicia sobre cuyo contenido y aplicación en casos concretos no decida el propio pueblo, sino cualquier otra instancia que, de esta manera, determina quién es el enemigo. Mientras un pueblo exista en el ámbito de lo político, debe, aunque sólo sea en el caso más extremo -pero, sobre cuya existencia decida por sí mismo- determinar la distinción entre amigo y enemigo. Ahí radica la esencia de su existencia política. Si ya no tiene la capacidad o voluntad de hacer distinción, deja de existir políticamente. Si un extranjero le dice quién es su enemigo y contra quién se puede o no combatir, entonces ya no es un pueblo políticamente libre. Una guerra tiene sentido no porque se la hace por altos ideales o por las normas jurídicas, sino porque se la hace contra su propio enemigo. Todo enturbiamiento de esta categoría - del amigo y enemigo- se puede explicar porque se confunde con algunas abstracciones o normas.

Por lo tanto, un pueblo políticamente existente no puede renunciar a distinguir, en caso necesario, al amigo y enemigo, por decisión propia y bajo su propio riesgo. $\mathrm{Si}$ desaparece esta distinción, entonces desaparece la vida política en general. Un pueblo, bajo ninguna circunstancia, es libre para renunciar a esta fatídica distinción por medio de proclamaciones y renuncias. Si una parte del pueblo declara que ya no conoce enemigos, lo que está haciendo es ponerse del lado de los enemigos, según sea la situación, y ayudarlos, pero la distinción entre amigos y enemigos no se elimina. Si una parte del pueblo declara que no conoce más enemigos, entonces ella, se ubica, según las circunstancias, del lado de los enemigos, y les ayuda; pero con eso no se elimina la distinción entre amigo y enemigo. Si los ciudadanos de un Estado dicen, personalmente, que no tienen enemigos, no tiene nada que ver con esta cuestión; ya que, un ciudadano particular no tiene enemigos políticos, lo máximo que puede querer decir con esas declaraciones es que quisiera apartarse de la totalidad política a la que pertenece, de acuerdo a su existencia, y vivir solamente como un ciudadano particular. También sería un error creer que un solo pueblo pudiera eliminar, por medio de una declaración de amistad a todo el mundo o desarmándose voluntariamente, la distinción entre amigo y enemigo. El mundo no se despolitiza de esta manera y tampoco se ubica en un estado de pura moralidad o economicidad. Cuando un pueblo teme el sufrimiento y el riesgo de la existencia política, encontrará otro pueblo que disminuirá su sufrimiento mediante la "protección contra los enemigos exteriores" y, con ello, también asumirá el dominio político, entonces el protector será el que determine quién es el enemigo, por la eterna conexión que existe entre protección y obediencia ${ }^{9}$. Sería tonto [tölpelhaft $]$ creer que un pueblo indefenso sólo tiene amigos y un cálculo perturbador [krapulose], suponer que el enemigo podría conmoverse, tal vez, por la falta de resistencia. Así como una persona, por renunciar a la productividad estética o económica no puede trasladar al mundo a un estado de

De jure belli ac pacis, 1, I, c. I, N. 2: "Justitiam in definitione (sc. belli) non includo".

9 Esta "mutual relation between protection and obedience" ha querido traer Hobbes, por medio del Leviatan, a la conciencia, cf. el comentario final de la edición inglesa de 1651, p. 396. 
pura moralidad, tampoco un pueblo puede conseguir un estado puramente moral o económico para la humanidad, por renunciar a la decisión política. Que un pueblo ya no tenga la fuerza o la voluntad para mantenerse en la esfera de lo político, no desaparece lo político del mundo. Tan solo desaparece un pueblo débil.

\section{6}

Del rasgo conceptual de lo político se deriva el pluralismo de los Estados. La unidad política presupone la posibilidad real del enemigo y, por lo tanto, otra unidad política, coexistente. Por este motivo, mientras exista un Estado, siempre habrá otros sobre la tierra y no puede haber un "Estado" mundial que abarque toda la tierra y a toda la humanidad. El mundo político es un pluriversum, no un universum. En este sentido, toda teoría del Estado es "pluralista", aunque en un sentido diferente a la teoría pluralista de Laski discutida anteriormente. La unidad política no puede, por su naturaleza, ser universal. Si los distintos pueblos y grupos de personas de la tierra estuvieran tan unidos que un combate entre ellos sería realmente imposible, pues la distinción entre amigo y enemigo terminaría incluso como una simple posibilidad, entonces sólo habría Economía, Moral, Derecho, Arte, etc., pero ya no habría ni política y ni Estado. No sé, si y cuando, la tierra y la humanidad entrará en esta situación. Por ahora no lo está. Sería una ficción deshonesta [unehrliche Fiktion] aceptarla como existente y una confusión evidente creer que, porque hoy cualquier guerra entre las grandes potencias se convierte fácilmente en una "guerra mundial", la finalización de esa guerra debería significar la "paz mundial" y, por lo tanto, ese idílico estado final de ausencia de Estado [Staatenlosigkeit].

La humanidad como tal no puede hacer guerra alguna, porque no tiene ningún enemigo, al menos no en este planeta. El concepto de humanidad excluye el concepto de enemigo, porque el enemigo no deja de ser una persona y, por lo tanto, la distinción específica se suprime. Que se hagan guerras en nombre de la humanidad no es ninguna refutación de esta simple verdad, sino que tiene solamente un sentido político particularmente intensivo. Cuando un Estado combate a su enemigo político en nombre de la humanidad, no es guerra de la humanidad, sino una guerra que hace un determinado Estado contra otro. El nombre de humanidad sólo podría tener el terrible significado de que al enemigo se le niegue la cualidad de hombre y, de esta manera, la guerra se volverá particularmente inhumana, porque no se puede manejar tales "nombres" sin ciertas consecuencias. Pero, aparte de este abuso eminentemente político del nombre apolítico de la humanidad, no hay guerras de la humanidad como tal. La humanidad no es un concepto político, tampoco se corresponde con una unidad política o comunidad política ni status político. La humanidad a la que refieren las doctrinas del derecho natural y liberal-individualistas es una sociedad universal, es decir, una que abarca a todos los hombres de la tierra, un sistema de relaciones entre individuos que existe verdaderamente cuando la posibilidad real del combate se ha excluido y toda agrupación de amigos y enemigos se ha vuelto imposible. En esta sociedad universal no habrá pueblos como unidades políticas y, por lo tanto, tampoco Estado.

La idea de una Liga de los Pueblos corresponde, hasta ahora, solamente a una tendencia poco clara, para conseguir un estado apolítico de la sociedad universal de la "humanidad". Además, casi siempre, de forma acrítica se exige que esta Liga de los Pueblos sea universal, es decir, que abarque a todos los Estados de la tierra. Pero, la universalidad significaría la absoluta despolitización y, con ello, la ausencia de Es- 
tado [Staatenlosigkeit]. Por eso, la institución ginebrina fundada en 1919, conocida como "Liga de los Pueblos" [Völkerbund] o mejor, según su nombre oficial, como "Völkergesellschaft" (Société des Nations), parece más contradictoria. Esta Liga de los Pueblos es una estructura interestatal que señala Estados como tales, regula algunas de sus relaciones recíprocas e incluso garantiza su existencia política. Ella, no sólo que no es universal, sino que ni siquiera es una organización internacional, si se distingue como es correcto y honesto, y se la reserva sólo para los movimientos realmente internacionales, es decir, para aquellos que, pasando las fronteras de los Estados y atravesando sus muros, ignoran la actual impermeabilidad del Estado como, por ejemplo, la Tercera Internacional. Aquí se muestra las contradicciones elementales entre internacional e interestatal, entre sociedad-universal despolitizada y la garantía interestatal del status quo de las actuales fronteras estatales, y es difícil de comprender cómo un tratamiento científico de la "Liga de los Pueblos" [Völkerbundes] pudo dejar pasar e incluso apoyar la confusión. La Sociedad de las Naciones de Ginebra no anula la posibilidad de las guerras, como tampoco suprime los Estados. Ella introduce nuevas posibilidades de guerras, permite las guerras, promueve las guerras de coalición y elimina una serie de inhibiciones, legitimando otras guerras. Tal como existe hasta hoy es un sistema de conferencias diplomáticas combinado con una oficina administrativa, la Secretaría General. Ella, como he mostrado en otra ocasión ${ }^{10}$, no es una liga, pero tal vez, una alianza. El auténtico concepto de la humanidad sigue siendo efectivo en la medida en que su verdadera actividad se encuentra en el ámbito humanitario, no político, y tiene al menos una "tendencia" hacia la universalidad; sin embargo, teniendo en cuenta su verdadera constitución e incluso dentro de esa llamada "Liga", permanece la posibilidad de una guerra, además, esa "tendencia" es en realidad sólo una frase. Desde luego, una Liga de pueblos no universal sólo puede conseguir relevancia política si es una alianza, una coalición. De ese modo no se eliminaría el jus belli. Una Liga de los pueblos como una organización universal de la humanidad tendría que llevar a cabo la difícil tarea, en primer lugar, arrebatar efectivamente el jus belli a todas las agrupaciones humanas existentes y, en segundo lugar, no asumir el jus belli, porque, de lo contrario, la universalidad, la humanidad, la sociedad, en pocas palabras, todos los rasgos esenciales volverían a desaparecer.

Si un "Estado mundial" abarcara toda la tierra y toda la humanidad, entonces no sería una unidad política y sólo como una forma de decirlo podría llamarlo Estado. Si toda la humanidad y toda la tierra estuvieran unidas sobre la base de una unidad económica y de técnicas de transporte [verkehrstechnischen], entonces sería una unidad "social", es decir, una "sociedad" que busca el punto de discrepancia entre los polos de la ética y la economía. Tampoco sería un "imperio", sino que tendría que perder todo carácter político.

\section{7}

Se podría comprobar todas las teorías del Estado y las ideas políticas sobre la base de su antropología y luego clasificarlas de acuerdo al supuesto, consciente o inconsciente, de un hombre "malo por naturaleza" o "bueno por naturaleza". La distinción es muy concisa y no es necesario tomarla en un sentido moral o ético. La valoración positiva o negativa del ser humano es decisiva como supuesto para una mayor argu-

10 Die Kernfrage des Völkerbundes [La Pregunta Central de la Sociedad de las Naciones], Berlin 1926. 
mentación ${ }^{11}$. He mostrado a menudo que la oposición entre las llamadas teorías del Estado autoritarias y anarquistas en particular, puede atribuirse a estas fórmulas ${ }^{12}$. Algunas teorías y construcciones que presuponen al individuo como "bueno" son liberales y anti-políticas sin ser, realmente, anarquistas. En el anarquismo abierto es más fácil observar lo estrechamente vinculadas que están la creencia en la bondad "natural" con la negación radical del Estado, la una deriva de la otra y se apoyan mutuamente. Para los liberales, sin embargo, la bondad del hombre no es otra cosa que un argumento mediante el cual, el Estado se pone al servicio de la "sociedad", es decir, que la "sociedad" es buena y que el Estado es su subordinado sospechosamente controlado. La clásica formulación se encuentra en Thomas Paine: la sociedad (society) es el resultado de nuestras necesidades racionalmente reguladas, el Estado (government) es el resultado de nuestros vicios ${ }^{13}$. El radicalismo antiestatal crece conforme a la medida de la creencia en la bondad radical de la naturaleza humana. El liberalismo burgués nunca fue radical en un sentido político. No es necesario decir que sus negaciones del Estado y de lo político tienen un sentido político específico y se dirigen contra una determinada forma de Estado. Pero no son, en realidad, ni una verdadera teoría del Estado ni una idea política. El liberalismo no ha negado radicalmente el Estado, pero tampoco ha encontrado una teoría positiva del Estado ni una forma propia de Estado, sino que solamente ha buscado vincular lo político con lo ético y someterlas a lo económico; el liberalismo ha creado una doctrina de la división y equilibrio de "poderes", es decir, un sistema de impedimentos y controles del Estado, pero no se puede llamar teoría del Estado.

Sin embargo, permanece la curiosa y para muchos, seguramente inquietante observación de que todas las teorías políticas genuinas presuponen al ser humano como "malvado", es decir, que lo evalúan negativamente. Esto lo puede demostrar fácilmente cualquier pensador específicamente político. Es suficiente, con mencionar los

11 Las singulares modificaciones y variaciones de esta distinción entre el bien y el mal no se discutirán aquí. La "maldad" puede mostrarse como corrupción, debilidad, cobardía, estupidez, pero también como "salvajismo", instinto, impulsividad, vitalidad, irracionalidad, etc., la "bondad" en variaciones equivalentes como la racionalidad, perfectibilidad, etc. Por lo tanto, para nuestra consideración es una sutileza innecesaria, cuando Dilthey [La cosmovisión y análisis del hombre desde Renacimiento y la Reforma, Tratado II, 1914, p. 3 [Weltanschauung und Analyse des Menschen seit Renaissance und Reformation, Schrift, II, 1914, p. 31], señala: "El hombre no es, según Maquiavelo, malo por naturaleza. Algunos pasajes parecen decirlo... Pero, en general, él, solamente quiere decir que el hombre tiene una irresistible inclinación a pasar del deseo al mal, si nadie lo contrarresta: animalidad, instinto, afecto son el núcleo de la naturaleza humana, especialmente el amor y el temor. Él, es inagotable en sus observaciones psicológicas sobre el juego de los afectos... De este rasgo fundamental de la naturaleza humana de donde se deriva la ley fundamental de toda vida política”. Con gran acierto dice Ed. Spranger en el capítulo "El hombre de poder" [Der Machtmensch] de sus "Formas de vida" [Lebensformen]: "Para el político, la ciencia del hombre, se encuentra, naturalmente, en primer plano de interés". Me parece que Spranger considera este interés demasiado técnico, como el interés en el "mecanismo instintivo" [Triebmechanismus] de los hombres. En la exposición ulterior de este capítulo, extraordinariamente rico en ideas y observaciones, se distinguen una y otra vez los fenómenos específicamente políticos y toda la existencialidad de lo político, a menudo en abrumadora cercanía [überwältigender Greifbarkeit]; prácticamente, carece de un fenómeno importante. Por ejemplo, la frase "la dignidad del tipo de poder parece crecer con su esfera de influencia", encuentra, en la esfera de lo político, un lugar para la verdad. También la famosa frase de Hegel del cambio de cantidad en cualidad tiene, como muchas otras, un sentido político. Un poder simplemente económico logró, con cierto alcance cuantitativo, el punto de lo político y "lo transformó".

12 Politische Theologie [Teología Política], 1922, pp. 50 ss.; Die Diktatur [La Dictadura], 1921, pp. 9, 109, 112 ss., 123,148 .

13 Cf. Die Dikatur, op. cit., p. 114. La formulación más concisa del Tribun du peuple de Babeuf: Toute institution qui ne suppose pas le peuple bon et le magistrat corruptible... [est vicieuse]. 
nombres de Maquiavelo, Hobbes, Bossuet, Fichte (tan pronto como se olvida de su idealismo humanitario), De Maistre, F. J. Stahl, Donoso Cortés, H. Taine; Hegel muestra también aquí su doble cara [Doppelantlitz]. A pesar de que pueden ser diferentes en la forma, el rango y la importancia histórica de esos pensadores, están de acuerdo en la evaluación negativa de la naturaleza humana en la misma medida en que se muestran como pensadores específicamente políticos.

La cuestión no se resuelve con observaciones psicológicas sobre el "pesimismo", tampoco al modo anarquista, invirtiendo lo dicho: que sólo son malos aquellos sujetos que consideran malo al ser humano. Por el contrario, es importante tener en cuenta hasta qué punto son diferentes las condiciones "antropológicas" en los diversos ámbitos del pensamiento humano. Un pedagogo considerará, por necesidad metodológica, al ser humano como educable. Un jurista, de derecho privado, parte de la frase: "unus quisque praesumitur bonus"14. Un teólogo deja de ser teólogo cuando ya no considera al individuo como pecaminoso y necesitado de redención, y ya no distingue entre redimidos de no-redimidos, entre elegidos de no-elegidos, mientras que el moralista presupone la libertad de elección entre el bien y el mal ${ }^{15}$. Puesto que la esfera de lo político se determina en última instancia por la posibilidad real de un enemigo, las representaciones y pensamientos políticos no pueden tomar como punto de partida un optimismo antropológico. De lo contrario, con la posibilidad del enemigo se anularía también toda consecuencia específicamente política. La relación de las teorías políticas con los dogmas teológicos del pecado es particularmente llamativa en Maistre, Donoso Cortés y F. J. Stahl, con innumerables cambios, pero intensamente efectiva; esta afinidad se explica a partir de estos supuestos teóricos. El dogma teológico fundamental de la pecaminosidad del mundo y del ser humano, así como la distinción entre amigo y enemigo, conduce a la división de personas y hace imposible el optimismo indiscriminado del concepto de hombre [Menschen]. En un mundo bueno, entre seres humanos buenos, naturalmente, reina la paz y la armonía entre todos, y los sacerdotes y los teólogos aquí son tan innecesarios como los políticos y estadistas [Staatsmänner]. El significado sociológico de la negación del pecado original, han mostrado Troeltsch (en sus "[Die] Soziallehren der christlichen Kirchen [und Gruppen, 1912]" [Las doctrinas sociales de las iglesias cristianas]) tomando como ejemplo numerosas sectas. El nexo metodológico entre los supuestos teóricos teológicos y políticos es claro. Pero el respaldo teológico siempre compromete a los conceptos estrictamente políticos, porque normalmente desplaza la distinción a lo religioso, o al menos, se mezcla con la teología moral. Teóricos de la política como Maquiavelo, Hobbes, frecuentemente también Fichte, de hecho, con su "pesimismo", sólo presuponen la realidad o la posibilidad real de la distinción de

14 El liberal Bluntschli, Lehre vom modernen Staat II, "Politik als Wissenschaft", Stuttgart, 1876, p. 559, válida contra el sistema de partidos de Stahl que la jurisprudencia (a la que, por cierto, no se trata este sistema de partidos) no procede de la maldad de los hombres, sino de la "regla de oro del jurista": Quivis praesumitur bonus, mientras que Stahl, acorde al modo de los teólogos, coloca la pecaminosidad radical [Sündhaftigkeit] de los hombres en la cúspide de la lista de sus pensamientos. La jurisprudencia es para Bluntschli, naturalmente, prudencia del derecho civil (cf. arriba, nota 1). La regla de oro del jurista tiene sentido en la regulación de la carga de pruebas.

15 En la medida en la que la teología se convierte en teología moral, surge este punto de vista de la libertad de elección y se desvanece la doctrina de la pecaminosidad radical del ser humano. "Homines liberos esse et eligendi facúltate praeditos; nec proinde quosdam natura bonos, quosdam natura malos", Irenaeus, Contra haereses IV, c. 37, Migne VII, p. 1099. 
amigo y enemigo. En Hobbes - con mucho, el más grande y quizás el único pensador político realmente sistemático- el "Bellum" de todos contra todos no se puede entender como el resultado de una fantasía asustada y perturbada, pero tampoco como "competencia" [Konkurrenz] (Tönnies), sino como presupuestos elementales de su sistema de pensamiento específicamente político.

Puesto que siempre tienen los ojos en la existencialidad concreta de un posible enemigo, estos pensadores políticos manifiestan frecuentemente un tipo de realismo que puede asustar a las personas que necesitan seguridad. Se puede decir -sin querer decidir sobre la cuestión de las cualidades naturales del hombre- que las personas generalmente aman la ilusión de una paz sin perturbaciones y no toleran a los "pesimistas". Por esta razón, para los opositores políticos de una teoría política clara no es difícil hablar de cinismo o de una vil inmoralidad y así causar una gran impresión. Pero esto no resuelve el problema científico, más bien la cofunde. La peor confusión generalmente se produce cuando el concepto de derecho es utilizado políticamente, de tal manera que impide un pensamiento político claro y oculta las propias aspiraciones políticas. El derecho, ya sea privado o público, tiene su propio círculo relativamente independiente. Pero, como todas las esferas de la vida y el pensamiento humano, puede ser utilizado para apoyar o impugnar otra esfera. Desde el punto de vista del pensador político es evidente, ni profano ni inmoral, prestar atención al sentido político de tales énfasis en la valorización del derecho o la moral. Sobre todo, siempre tendrá que hacer preguntas más específicas con respecto a términos [Redewendung] como "dominio" o incluso sobre la "soberanía" del derecho, por ejemplo, en primer lugar, si el "derecho" se refiere a las leyes positivas y métodos legislativos que debería seguir aplicándose, entonces el "estado del derecho" no significa aquí sino la legitimación de un determinado status quo que, naturalmente, todos tienen interés de conservarlo, aquellos cuyo poder político o económico se estabiliza en ese derecho. En segundo lugar, la apelación del derecho podría significar que un derecho superior o más correcto, un llamado derecho natural o derecho de la razón, se opone al derecho del status quo, entonces, para un político es evidente que ese "dominio" o "soberanía" del derecho significa el dominio y la soberanía del pueblo, quien puede invocar el derecho superior y decidir sobre él, cuál es su contenido y cómo debe ser aplicado. Hobbes, con más claridad que todos los demás, ha extraído estas simples consecuencias del pensamiento político de forma resuelta y lo manifestó en reiteradas ocasiones, que la soberanía del derecho significa únicamente la soberanía de las personas que establecen y aplican la ley, que el dominio de un "orden superior" es una frase vacía sino tiene el sentido político, de que ciertas personas a causa de este orden superior quieren dominar sobre las personas de un "orden inferior". El pensamiento político es aquí, en la autonomía y unidad de su esfera, sencillamente irrefutable, porque siempre son grupos concretos de personas los que combaten en nombre del "derecho" o de la "humanidad" o del "orden" o de la "paz" contra otro grupo concreto de personas, y el teórico de la política pura si sigue siendo consecuentemente con su pensamiento político, puede reconocer, una y otra vez, incluso en la acusación de inmoralidad y cinismo, tan sólo un medio político de personas que combaten concretamente.

Por lo tanto, el pensamiento político y el instinto político se prueban, en la teoría y en la práctica, en la capacidad para distinguir al amigo y enemigo. Al contrario: en cualquier parte de la historia política, tanto en política exterior como en política interior, aparece la incapacidad o la falta de voluntad para hacer esta distinción 
como síntoma del fin político. En Rusia, las clases decadentes idealizaron, antes de la revolución, al campesino ruso como el Muschik bueno, valiente y cristiano. En una Europa agotada, una burguesía relativista convirtió a todas las culturas exóticas imaginables en objeto de su consumo estético. Antes de la Revolución de 1789, los aristócratas en Francia se habían entusiasmado con el pueblo bueno y virtuoso. Tocqueville describe en su exposición del Ancien Régime (p. 228) esta situación en frases veladas, cuya tensión procede, en él mismo, de un pathos específicamente político: nadie experimentaba nada de la Revolución; es curioso ver la seguridad con la que, los privilegiados hablaban sobre la bondad, la benevolencia e inocencia del pueblo, cuando 1793 ya estaba bajo sus pies: "spectacle ridicule et terrible".

\section{8}

El liberalismo del último siglo transformó y desnaturalizó todas las nociones estatales y políticas de una forma singular y sistemática. El liberalismo, como realidad histórico-política, apenas se ha escapado de la política como cualquier movimiento humano significativo. Los liberales de todos los países han impulsado la política igual que otras personas y se han fusionado en diferentes maneras con elementos e ideas no-liberales, como nacional-liberales, social-liberales, conservadores liberales, católicos liberales, etc. ${ }^{16}$. En particular, se han asociado con fuerzas de la democracia completamente iliberal [unliberalen], porque son esencialmente políticas ${ }^{17}$. Sin embargo, la pregunta es, si del concepto puro y consecuente del liberalismo individualista se puede obtener una idea específicamente política. La respuesta es negativa. Porque la negación de lo político que se encuentra en todo individualismo consecuente, conduce, probablemente, a una práctica política de la lucha contra la desconfianza de todas las fuerzas políticas y formas de Estado imaginables, pero nunca a su propia teoría positiva del Estado y de la política. Por lo tanto, existe una política liberal como oposición contra las restricciones estatales, eclesiásticas u otras, de la libertad individual, como la política comercial, eclesiástica, educativa o cultural, pero no una política liberal sin más, ni una política exterior que no sea una crítica a los "ataques". La teoría sistemática del liberalismo se refiere, casi exclusivamente, a la lucha política interna contra el poder del Estado y consiste en una serie de métodos para compartir, impedir, equilibrar, controlar ese poder estatal y hacer del estado un compromiso y de las instituciones estatales una "válvula" para la protección de la

16 La elaboración podría incrementarse fácilmente. El romanticismo alemán de 1800 a 1830 es un liberalismo tradicional -y feudal-, es decir, sociológicamente hablando, un moderno movimiento burgués, en el cual la burguesía [Bürgertum] no era lo suficientemente fuerte para eliminar el poder político de la tradición feudal existente en aquella época, y por esa razón trató de buscar con él una alianza análoga, posteriormente con el nacionalismo democrático y el socialismo. A partir de un liberalismo burgués consecuente no se permite ganar, precisamente, ninguna teoría política. Esta es la razón última de que el romanticismo no puede tener ninguna teoría política, sino que siempre adaptarse a las energías políticas dominantes. Los historiadores que quieren, como G. von Below, ver, siempre y sólo, un romanticismo “conservador”, deben ignorar los vínculos. Los tres principales heraldos literarios de un parlamentarismo típicamente liberal son tres románticos típicos: ¡Burke, Chateaubriand y Benjamin Constant!

17 Sobre la oposición entre liberalismo y democracia, cf. Carl Schmitt, Die geistes geschichtliche Lage des heutigen Parlamentansmus, $2^{\mathrm{a}}$ ed., 1926, pp. 13 y ss.; además el artículo de F. Tönnies, "Demokratie und Parlamentarismus", Schmollers Jahrbuch 51 (abril 1927), pp. 173 y ss., que reconoce también la rigurosa separación entre el liberalismo y la democracia; cfr. finalmente el interesantísimo artículo de $H$. Hefele en la revista "Hochland", noviembre de 1924 [octubre de 1924, 34-43]. 
libertad individual y de la propiedad privada. Esto no se puede llamar ni una forma de estado ni una teoría de Estado, aunque usualmente, se llama a sí misma como teoría del "Estado de derecho".

El pensamiento liberal, de modo extremadamente sistemático, elude o ignora al Estado y la política y se mueve en una típica y siempre recurrente polaridad de dos esferas heterogéneas, concretamente, entre la ética y la economía. La desconfianza frente al Estado y la política se explica fácilmente a partir de los principios de un sistema para el cual, el individuo debe permanecer terminus a quo y terminus ad quem. La unidad política debe, en caso necesario, exigir el sacrificio de la propia vida. Para el individualismo del pensamiento liberal esta posibilidad no puede ser alcanzada y justificada de ningún modo. Un individualismo que le otorgue la disposición de la vida física sobre este individuo a otro que no sea el mismo, obviamente, sería una frase vacía. Para el individuo como tal, no hay enemigo con el que tendría que luchar a vida o muerte, si personalmente, no quiere; obligarlo a luchar contra su voluntad es, en todo caso, desde el punto de vista del individuo particular, falta de libertad y violencia. Todo el pathos liberal se opone contra todo tipo de uso de violencia y falta de libertad. Cada perjuicio, cada amenaza de esta libertad individual, de la propiedad privada y la libre competencia se llama "violencia" y es, eo ipso, algo malo o incluso, como le gusta decir a Locke, el verdadero fundador del llamado Estado de derecho, algo animal. Así es como se llega a todo un sistema de conceptos desmilitarizados y despolitizados, de los cuales, algunos pueden enumerarse aquí para mostrar la asombrosa coherencia, y todavía hoy, la indudable dominación del sistema de pensamiento liberal, a pesar de los aparentes contratiempos. Siempre se debe tener en cuenta que estos conceptos liberales se mueven de forma típica entre la ética ("espiritualidad") y la economía, y tratan de disolver lo político desde esos polos, por lo cual, el concepto de "derecho", es decir, del "estado de derecho privado" sirve como palanca, y el concepto de propiedad privada constituye el centro del globo, cuyos polos -ética y economía- son simplemente emisiones opuestas de ese centro. El pathos ético y la objetividad económica materialista se combina en cada declaración típicamente liberal y a cada concepto político le proporciona un rostro diferente. Así, en el pensamiento liberal, el concepto político de "lucha" deviene, por el lado económico, en competencia y, por el lado "espiritual", en discusión; en lugar de clara distinción entre los dos estados diferentes, "guerra" y "paz", surge el estado permanente de la eterna competencia y de la eterna discusión. El Estado se convierte en Sociedad, por un lado, por el ético-espiritual, en un concepto ideológico-humanitario de la humanidad; por otro lado, en la unidad económica-técnica de un sistema unificado de producción y transporte [Verkehrs-Systems]. La voluntad, completamente lógica, de rechazar al enemigo en una situación de lucha dada, se transforma en un programa racionalmente-construido, en una tendencia o un cálculo económico. El pueblo se convierte, por un lado, en un público culturalmente interesado, por otro lado, en parte, en una empresa y personal de trabajo, en parte, en una masa de consumidores. Por el lado espiritual, la dominación y el poder, se convierten en propaganda del "control" económico.

Todas estas resoluciones pretenden, con toda seguridad, someter al estado y la política, en parte, a una moral individualista y, por lo tanto, del derecho privado, y en parte, a categorías económicas, despojándoles de su sentido específico. Es muy curioso, cómo el liberalismo, no sólo reconoce la relativa "autonomía" de las diversas áreas de la vida humana fuera de lo político, sino que exagera hasta el absoluto ais- 
lamiento. Sí, le gusta reconocer, por ejemplo, la autonomía de los valores estéticos y la libertad del genio artístico, en algunos países un genuino pathos liberal surge cuando la libertad del arte fue amenazada por el moralismo de los "apóstoles de la moralidad". A su vez, la moral frente a la religión se vuelve autónoma. Sin embargo, lo más importante de todo, con absoluta seguridad, la autonomía de las normas y las leyes de la economía, probablemente sea uno de los pocos principios realmente vigentes y completamente indiscutibles del mundo actual y que la producción y el consumo, la rentabilidad y el mercado tengan su propia esfera y no puedan ser dirigidos por la ética o la estética o la religión. Aún más interesante es que lo político, con un pathos especial, es privado de toda autonomía y sometido a las normas y reglamentos de la moral y del derecho. Puesto que, en la realidad concreta del ser político no hay órdenes y series de normas abstractas, sino siempre, personas o asociaciones concretas que dominan sobre otros, también aquí, naturalmente, desde el punto de vista político, el "dominio" de la moral, del derecho o la "norma" siempre tienen un sentido político concreto ${ }^{18}$.

Desde el principio, el pensamiento liberal planteó contra la política [die Politik] la acusación de "violencia". Esto puede surgir de una auténtica convicción moral, pero considerada políticamente, puede significar que una posición de poder basada en el derecho privado y la superioridad económica, considere cualquier corrección que se realice desde otra parte, ya sea desde lo político o desde lo religioso, como "violencia extra-económica" [Außerökonomische]. Es instructivo observar con qué naturalidad, en primer lugar, se califica como violencia a lo extra-económico y luego se levanta esa acusación de violencia. Desde las últimas décadas, las definiciones de Franz Oppenheimer, son un magnífico ejemplo de este método liberal. Oppenheimer proclamó como su objetivo la "exterminación del Estado". El liberalismo se vuelve tan radical que ni siquiera permite considerar al Estado como un operador armado [bewaffneten Bürodiener]. La "exterminación" se pone inmediatamente en acción, por medio de una definición cargada de valor y afecto. Según Oppenheimer, el concepto del Estado se determina por los "medios políticos" y el concepto de la sociedad (esencialmente apolítica) por los "medios económicos". Las definiciones, por medio de las cuales, lo político se distingue de los medios económicos no son más que eufemismos característicos de ese pathos contra el Estado y la política que se mueve entre la polaridad de la ética y la economía. El intercambio es considerado como medio económico, es reciprocidad de prestación y contraprestación, por ello, justicia, y finalmente, nada menos que "el espíritu corporativo de la armonía, fraternidad y justicia" en sí mismas ${ }^{19}$. Por el contrario, los medios son el robo, la violencia y la

18 La estructura ideológica del Tratado de Versalles responde exactamente a esta polaridad del pathos ético y cálculo económico. En el artículo 231 se obliga al Reich alemán a reconocer su "responsabilidad" por todos los daños y víctimas de la guerra, lo cual establece la base para un juicio de valor jurídico y moral. Se evitan conceptos políticos como el de "anexiones"; la cesión de Alsacia y Lorena es una "desanexión", por lo tanto, la reparación de una injusticia. La cesión de territorios polacos y daneses sirve a la exigencia ideal del principio de nacionalidad; la incautación de colonias que se proclama en el artículo 22 incluso como un acto desinteresado de humanidad. El polo económico opuesto de este idealismo son las reparaciones de guerra, es decir, una continua e ilimitada explotación económica, de los vencidos. Resultado: un acuerdo de este tipo no podía hacer realidad un concepto político como la "paz", de modo que siempre fueron necesarios nuevos tratados de paz "verdaderos": el Protocolo de Londres de agosto de 1924 (Plan Dawes), Locarno de octubre de 1925, el ingreso en la Sociedad de las Naciones [Völkerbund] en septiembre de 1926..., la lista todavía no ha terminado.

19 Cf. la compilación de F. Sander, "Geselleschaft und Staat, Studien zur Ge sellschaftslehre von Franz Oppenheimer", Archivo para Ciencia y Política Social [Archiv für Sozialwissenschaft und Sozialpolitik]. 56 (1926), p. 384. 
conquista, "la conquista de la violencia extra-económica", crímenes de todo tipo. El orden jerárquico de los valores de la relación entre el Estado y la sociedad permanece intacto, pero mientras la concepción del Estado del siglo XIX alemán, sistematizada por Hegel, construía un Estado sobre una sociedad "egoísta", como un reino de la moralidad, ahora la jerarquía de valores se ha invertido y la sociedad ha surgido como un reino de la justicia pacífica sobre el Estado, eso parece una esfera de robo y violencia. Los papeles están invertidos, la apoteosis permanece. Pero, en realidad, no es aceptable, ni lógico, ni moral, ni psicológicamente correcto, definir simplemente con descalificaciones morales y colocar, como "concepto", el intercambio bueno y justo al lado del vulgar robo. Con tales determinaciones conceptuales se podría definir la política [die Politik] como la esfera de la lucha honesta y la economía como un mundo del fraude, porque, después de todo, la relación de lo política con el robo y la violencia no es más específica que la economía con la astucia y el engaño. Existe, después de todo, como hecho sociológico, un dominio sobre las personas basado en la economía que, precisamente, cuando permanecen apolíticas, es decir, mientras evitan toda responsabilidad y visibilidad política, deben mostrarse como un fraude. El concepto de intercambio no excluye, conceptualmente, la idea de que uno de los adversarios sufra una desventaja y que un sistema de contratos de intercambios se convierta, finalmente, en un sistema de la peor explotación y represión. Si los explotados y oprimidos se defienden, no pueden hacerlo con medios económicos. También es evidente que los dueños del poder económico describan, cada modificación "extra-económica" de su posición de poder, como un acto de violencia y crimen y traten de impedirlo. Sólo así se suprime esa construcción ideal de una sociedad basada en el intercambio y eo ipso justa. La esfera del intercambio tiene sus límites estrechos y su área específica. No todas las cosas tienen un valor de cambio. Para la libertad política y la independencia política, por ejemplo, no existe un equivalente justo, por muy grande que pueda ser el soborno.

Con la ayuda de tales definiciones y construcciones que, finalmente, giran alrededor de la típica polaridad liberal de la ética individual y la economía, no se puede exterminar el Estado y la política y no se despolitizará el mundo. Que la posición de poder económica sea hoy, cada vez más fuerte y decisiva, sólo significa que se aproxima, más y más, al punto decisivo de lo político. Por lo tanto, fue equivocado pensar que una posición política alcanzada con ayuda de la superioridad económica sería "esencialmente no belicosa" (Schumpeter). Esencialmente no belicosa, y precisamente de acuerdo a la esencia de la ideología liberal, solamente es terminología. Un poder fundado económicamente buscará, naturalmente, crear un estado en la tierra, en el que pueda aplicar libremente sus medios económicos de poder, bloqueo de créditos, bloqueo de materias primas, destrucción de moneda, etc. El considerará como una "violencia extraeconómica", cuando un pueblo u otro grupo de personas intente eludir el efecto de esos métodos pacíficos. Además, cuando estos métodos ya no son suficientes, utilizará medios de coacción económica más severos, como se enumera, por ejemplo, en las "directrices" para la aplicación del artículo 16 del estatuto de la Sociedad de las Naciones de la $2^{\mathrm{a}}$ Asamblea de 1921. Bloqueo del abastecimiento de recursos alimenticios para la población civil (número 14 de las directrices) y bloqueo por hambre etc. Finalmente, también cuenta con medios técnicos para producir la muerte física violenta, y sería inútil esperar que las armas modernas increíblemente perfectas se produzcan, con semejante cantidad de capital e inteligencia, para que nunca se utilicen. Sin embargo, para la aplicación de tales medios, se está 
formado un nuevo vocabulario, esencialmente pacifista, que ya no conoce la guerra, sino únicamente ejecuciones, sanciones, expediciones de castigo, medidas pacíficas, protección de Tratados, la policía internacional, protección de la paz. El enemigo ya no se llama enemigo, sino, en cambio, es tratado como criminal o como "mad dog" y una guerra dirigida a la preservación o ampliación de una posición de poder económica se convierte, con una gran cantidad de propaganda, en una "cruzada" y en la "última guerra de la Humanidad". Esto es lo que exige la polaridad entre la ética y la economía. En él se muestra realmente la sistemática y asombrosa consecuencia del individualismo liberal, pero también este sistema apolítico e incluso antipolítico, o bien, se pone al servicio de la agrupación de amigos y enemigos existente, o bien, crea nuevas, pero no puede escapar de la consecuencia de lo político. 